\title{
Predicting Transdermal Uptake of Phthalates and a Paraben from Cosmetic Cream Using the Measured Fugacity
}

Eftekhari, Azin; Frederiksen, Hanne; Andersson, Anna Maria; Weschler, Charles J.; Morrison, Glenn

Published in:

Environmental Science and Technology

Link to article, DOI:

10.1021/acs.est.0c01503

Publication date:

2020

Document Version

Peer reviewed version

Link back to DTU Orbit

Citation (APA):

Eftekhari, A., Frederiksen, H., Andersson, A. M., Weschler, C. J., \& Morrison, G. (2020). Predicting Transdermal Uptake of Phthalates and a Paraben from Cosmetic Cream Using the Measured Fugacity. Environmental Science and Technology, 54(12), 7471-7484. https://doi.org/10.1021/acs.est.0c01503

\section{General rights}

Copyright and moral rights for the publications made accessible in the public portal are retained by the authors and/or other copyright owners and it is a condition of accessing publications that users recognise and abide by the legal requirements associated with these rights.

- Users may download and print one copy of any publication from the public portal for the purpose of private study or research.

- You may not further distribute the material or use it for any profit-making activity or commercial gain

- You may freely distribute the URL identifying the publication in the public portal 
Subscriber access provided by Uppsala universitetsbibliotek

\section{Ecotoxicology and Public Health}

\section{Predicting transdermal uptake of phthalates and a paraben from cosmetic cream using the measured fugacity}

Azin Eftekhari, Hanne Frederiksen, Anna-Maria Andersson, Charles J. Weschler, and Glenn C. Morrison

Environ. Sci. Technol., Just Accepted Manuscript • DOI: 10.1021/acs.est.0c01503 • Publication Date (Web): 20 May 2020

Downloaded from pubs.acs.org on May 21, 2020

\section{Just Accepted}

"Just Accepted" manuscripts have been peer-reviewed and accepted for publication. They are posted online prior to technical editing, formatting for publication and author proofing. The American Chemical Society provides "Just Accepted" as a service to the research community to expedite the dissemination of scientific material as soon as possible after acceptance. "Just Accepted" manuscripts appear in full in PDF format accompanied by an HTML abstract. "Just Accepted" manuscripts have been fully peer reviewed, but should not be considered the official version of record. They are citable by the Digital Object Identifier (DOI®). "Just Accepted" is an optional service offered to authors. Therefore, the "Just Accepted" Web site may not include all articles that will be published in the journal. After a manuscript is technically edited and formatted, it will be removed from the "Just Accepted" Web site and published as an ASAP article. Note that technical editing may introduce minor changes to the manuscript text and/or graphics which could affect content, and all legal disclaimers and ethical guidelines that apply to the journal pertain. ACS cannot be held responsible for errors or consequences arising from the use of information contained in these "Just Accepted" manuscripts. 


\section{Predicting transdermal uptake of phthalates and a paraben from cosmetic}

2 cream using the measured fugacity

3 Azin Eftekhari ${ }^{1}$, Hanne Frederiksen ${ }^{2}$, Anna-Maria Andersson ${ }^{2}$, Charles J. Weschler ${ }^{3,4}$, Glenn

4 Morrison $^{1 *}$

$5{ }^{1}$ Department of Environmental Sciences and Engineering, Gillings School of Global Public

6 Health, The University of North Carolina at Chapel Hill, North Carolina, United States of America

$7 \quad{ }^{2}$ Department of Growth and Reproduction and International Center for Research and Research

8 Training in Endocrine Disruption of Male Reproduction and Child Health (EDMaRC),

9 Rigshospitalet, University of Copenhagen, DK-2100 Copenhagen, Denmark

$10{ }^{3}$ International Center for Indoor Environment and Energy, Department of Civil Engineering,

11 Technical University of Denmark, Lyngby, 2800 Denmark

$12{ }^{4}$ Environmental and Occupational Health Sciences Institute, Rutgers University, Piscataway, New

13 Jersey 08901, United States

14 *Corresponding email: glenn.morrison@unc.edu

16 Abstract

17 Transdermal uptake models compliment in vitro and in vivo experiments in assessing risk of

18 environmental exposures to semi-volatile organic compounds (SVOCs). A key parameter for

19 mechanistic models is a chemical driving force for mass transfer from environmental media to

20 human skin. In this research, we measure this driving force in the form of fugacity for chemicals

21 in cosmetic cream and use it to model uptake from cosmetics as a surrogate for condensed

22 environmental media. A simple cosmetic cream, containing no target analytes, was mixed with

23 diethylphthalate (DEP), di-n-butylphthalate (DnBP), and butyl paraben (BP) and diluted to make

24 creams with concentrations ranging from $0.025 \%$ to $6 \%$. The fugacity, relative to the pure

25 compound, was measured using solid-phase micro extraction (SPME). We found that the

26 relationship between the concentration and fugacity is highly non-linear. The relative fugacity of 
27 the chemicals for a $2 \% \mathrm{w} / \mathrm{w}$ formulation was used in a diffusion-based model to predict 28 transdermal uptake of each chemical and compared with excretion data from a prior human subject 29 study with the same formulation. Dynamic simulations of excretion are generally consistent with 30 the results of the human subject experiment but sensitive to the input parameters, especially the 31 time between cream application and showering.

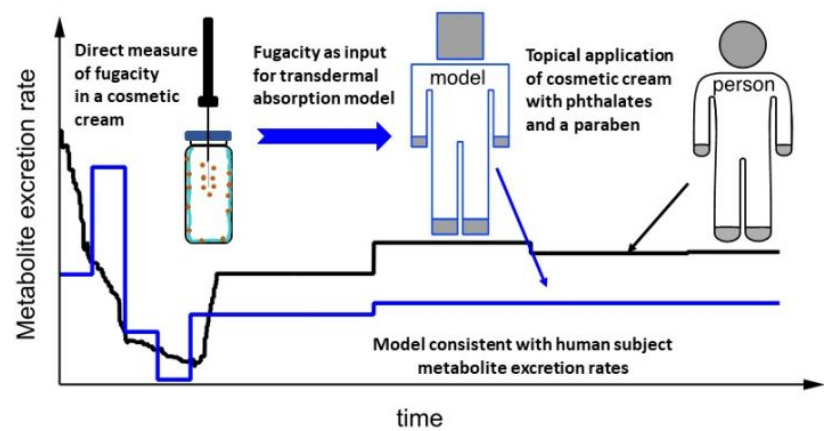

TOC Art

\section{KEYWORDS}

35 Dermal uptake, cosmetics, Chemical activity, Exposure model, Skin, Personal care products

1. Introduction

38 Many semi-volatile organic compounds (SVOCs) we encounter in indoor environments are

39 suspected, predicted, or confirmed endocrine disruptors ${ }^{1,2}$ and belong to classes of compounds

40 used as pesticides, plasticizers and flame retardants. Sources include building materials, cleaning

41 agents, pest control agents and personal care products. ${ }^{3-5}$ Recent studies suggest that transdermal

42 uptake of indoor SVOCs can be comparable to or greater than intake associated with inhalation ${ }^{4,6}$

43 or other exposure pathways. However, the dermal pathway is relatively poorly characterized for

44 contaminants of indoor origin. Therefore, validated, quantitative methods to directly assess or

45 predict exposure to these species are needed.

46 To assess individual and population dermal exposure to SVOCs present in our environment, a 47 variety of in vitro and in vivo methods have been developed. ${ }^{7-11}$ Transdermal uptake models 48 compliment in vitro and in vivo experiments in assessing risk of environmental exposure and dose.

49 Modeling is a particularly powerful tool if the models are representative and model parameters are 
50 well-characterized. Transdermal exposure models often make predictions based on available 51 information such as contact frequency, concentration of SVOCs in media, contact area and 52 duration, and transfer efficiency or fractional dose. While semi-empirical approaches such as these 53 can be rapidly and widely applied to many exposure scenarios, they are often limited by the need 54 to derive media-specific parameters such as transfer efficiency or permeability. Chemical activity 55 based mechanistic exposure models often require less information about the source media. They 56 instead rely on a measure or estimate of a chemical activity gradient, or fugacity gradient, that acts 57 as the driving force controlling transfer from sources to occupant.

58 The fugacity is a powerful concept that has been used to characterize contaminant transport among 59 many disciplines. The fugacity can be regarded as the partial pressure ( $\mathrm{Pa}$ ) exerted by a compound 60 within a medium on the surrounding environment and is a convenient measure of chemical activity 61 when referenced to the pure compound. The steady state permeation rate for a membrane such as 62 skin is proportional to the fugacity gradient across that membrane. ${ }^{12}$ Fugacity affects both the 63 direction of diffusion and the rate of diffusion. ${ }^{13-15}$ Net transfer continues from regions of higher 64 fugacity to regions of lower fugacity until a condition of equal fugacity, or equilibrium, is achieved. 65 The concept of fugacity has long been used in the field of chemical engineering in designing 66 processes such as distillation, gas absorption, solvent extraction, etc. ${ }^{15-20}$ The importance of 67 fugacity as an index of toxicity was later discussed by Ferguson..$^{21}$ Mackay ${ }^{22}$ expanded on the concept of fugacity in mass transfer models in environmental exposure studies. From then, fugacity

69 has been used extensively for modeling the transfer of chemicals among environmental media and 70 across biological membranes in environmental toxicology and risk assessment. ${ }^{23-41}$

71 There are relatively few controlled human subject experiments that provide direct, quantitative, 72 measurements of transdermal uptake from environmental compartments that provide sufficient 73 information to allow for testing of fugacity based models. Some examples include transdermal 74 uptake of SVOCs from air and clothing ${ }^{6,42-44}$ and halogenated organics from water during bathing 75 and swimming. ${ }^{45}$ Fortunately, there are excellent experiments in the cosmetics literature that can 76 be used as a proxy for contact with condensed environmental media. ${ }^{7-10}$ These experiments include 77 large numbers of human subjects, application of cosmetic products over large areas of the body 78 and measurments of urine and blood concentrations of target chemicals and their metabolites. They 79 also provide sufficient information about the composition of the cosmetic product so that product 
80 can be reproduced and the fugacity can be measured. From this measurement, we can determine if

81 the fugacity, in combination with mechanistic models, can reproduce the human subject 82 experimental results.

83 Personal care products (PCPs) are an important source of chemical exposure in the home 84 microenvironment. Dermal exposure to multiple endocrine disrupting chemicals (EDCs) through 85 daily application of lotions and creams is of concern. ${ }^{10,11,46-51}$ Sakhi et al. ${ }^{52}$ detected eleven 86 different metabolites of phthalates (a group of SVOCs) commonly used in personal care products 87 in urine samples of Norwegian mothers and children. They observed diurnally elevated concentrations of urinary EDC biomarkers, which can be due to morning and evening use of personal care products. This kind of diurnal pattern of metabolite concentrations in urine, an indirect measure of exposure to EDCs from use of PCPs, has been observed in other studies. ${ }^{53,54}$

91 Janjua et al. ${ }^{8,9}$ experimentally confirmed such an association with human subjects. They monitored

92 transdermal uptake of diethyl phthalate (DEP), dibutyl phthalate (DnBP) and butyl paraben (BP)

93 from dosed creams during whole-body topical application on a daily basis for a week on 26 male

94 subjects that acted as their own controls. They observed a significant increase in urine and plasma 95 concentrations of metabolites for all the chemicals after application of the dosed cream. ${ }^{9}$ A 96 analogous study was conducted for chemical UV filters known to be used in sunscreens, ${ }^{10}$ with 97 similar results.

98 Predicting the fugacity of PCPs can be challenging because, like many other environmental media, 99 PCP formulations can be quite complex. These mixtures or emulsions can be comprised of water, 100 oils, salts, polymers, solids and nanoparticles. ${ }^{55-58}$ Given the complexity and sometimes high 101 concentrations of target SVOCs, the mixtures may exhibit non-ideal behaviour and it may not 102 (currently) be possible to predict the chemical activity or fugacity from the composition. Therefore, 103 an independent measure of fugacity is valuable as media-independent input for mechanistic 104 models.

105 Our goal in this research is to demonstrat the applicability of using the directly-measured relative 106 fugacity as input to models of transdermal uptake of chemicals from complex environmental media 107 such as personal care products. Specific objectives include 1) measure fugacities of the three target 108 chemicals in the cosmetic cream formulation used in Janjua human subject study ${ }^{8,9}$ 2) assess the 
109 linearity of fugacity with respect to the concentration of chemicals in the cream mixtures, 3) use 110 the measured fugacities to predict transdermal uptake of the chemicals using an existing model ${ }^{59}$ 111 and 4) compare the predicted transdermal uptakes to Janjua human subject excretion data. ${ }^{9}$

112 2. Materials and Methods

113 2.1. Materials

114 WELLSKIN Glaxal Base (identical to the base cream used in the human subject studies by Janjua 115 et al. ${ }^{8,9}$ ) was purchased through Amazon. Ingredients as reported on its label are water, petrolatum, 116 cetearyl alcohol, paraffinum liquidum, cereareth-20, sodium phosphate and p-chloro-m-cresol. 117 Diethyl phthalate (DEP), di-n-butyl phthalate (DnBP) and butyl paraben (BP) with purity of 99\% 118 were purchased from Sigma-Aldrich. Screw cap clear glass vials $(20 \mathrm{ml})$ and screw caps with 18 $119 \mathrm{~mm}$ PTFE coated silicone septa were obtained from SUPELCO, USA. A $7 \mu \mathrm{m}$ 120 polydimethylsiloxane (PDMS) SPME fiber (fused silica, $23 \mathrm{Ga}$, green) was obtained from 121 SUPELCO for SPME analysis of cream samples.

123 Four different initial stock mixtures were prepared as follows: 6\% (w/w) DEP in Glaxal Base, 6\%

124 DnBP in Glaxal Base, 6\% BP in Glaxal Base (single-component creams), and 6\% each of DEP, 125 DnBP, and BP combined in Glaxal Base (three-component creams). Once the compounds were 126 added to the Glaxal Base, the creams were manually stirred for 2 minutes, 3-5 times a day for one 127 week, using a glass rod. At this time, we observed that mixture appeared (visually) to be uniform 128 and we considered each mixture to be fully mixed. We also checked the headspace SPME peak 129 area (see method in section 2.3) of three separate samples of each cream mixture to ensure that the 130 signal was the similar across these samples before making dilutions. Each of four stock creams 131 were sequentially diluted by factors of three, for final concentrations that ranged from $0.025 \%$ to $1326 \%$. Of these, the $2 \%$ three-component cream formula was identical to the one used in Janjua 133 human subject study. ${ }^{8,9}$ Between 0.5 to 0.6 gram of each diluted cream was added to a $20 \mathrm{ml}$ glass 134 vial that was then be sealed with a septa cap (triplicate of each concentration). Before being capped, 135 the mixture was spread over the entire inner surface of the headspace vial (excluding neck and 136 cap) using a glass stir rod to increase the exposed surface area of the mixture. This reduces 
137 variability in subsequent SPME sampling and reduces the time required for the cream mixture and 138 the air in the vial to reach equilibrium.

139 A vial of pure, unaltered base cream was prepared as a blank. Vials of pure DEP, DnBP and BP

140 were also prepared as fugacity references. To do this, a small volume of DEP and DnBP - enough 141 to coat the walls of the vial - were transferred to headspace vials. For BP, which is solid at room 142 temperature, about $0.5 \mathrm{~g}$ was added to a headspace vial, capped, and heated until it melted. The 143 inner walls were coated with melted BP and then allowed to cool so that a thin layer of solid BP 144 coated the inner surface of the vial.

146 Vapor-liquid phase equilibrium data have been commonly used to estimate fugacity of a compound 147 in a substrate. ${ }^{60,61}$ SPME (our chosen method) has been used for equilibrium sampling and 148 chemical activity measuring of environmental media in environmental toxicology and exposure studies. $^{62-68}$

An Agilent Technologies 7890A gas chromatograph with a flame ionization detector (GC-FID) system was used for headspace sample analysis. The GC column was a $30 \mathrm{~m} \mathrm{HP-5} \mathrm{5 \%} \mathrm{Phenyl}$ 152 Methyl Siloxane capillary $(30 \mathrm{~m} \times 320 \mu \mathrm{m}$ inner diameter $\times 0.25 \mu \mathrm{m}$ film thickness $)$. The sample, 153 via the SPME fiber, was injected to the GC inlet at a temperature of $260{ }^{\circ} \mathrm{C}$ and in splitless mode. 154 The carrier gas was nitrogen at a pressure of $6 \mathrm{psi}$ and a total flowrate of $50 \mathrm{ml} / \mathrm{min}$. The initial 155 oven temperature was $40^{\circ} \mathrm{C}$, held for $1 \mathrm{~min}$, then raised to $180^{\circ} \mathrm{C}$ at $15^{\circ} / \mathrm{min}$, held for 3 minutes, 156 then raised to a final temperature of $220{ }^{\circ} \mathrm{C}$ at $5{ }^{\circ} \mathrm{C} / \mathrm{min}$ for the total GC run of $26.3 \mathrm{~min}$.

157 Automatic SPME headspace sampling of the vials was carried out at $32^{\circ} \mathrm{C}$ using a $7 \mu \mathrm{m}$ PDMS 158 SPME fiber (fused silica, $23 \mathrm{Ga}$, green, suitable for extraction of SVOCs). The GC was equipped 159 with a Combi PAL auto sampler and all the steps of incubating, sampling, and injecting to GC 160 were performed automatically. The autosampler was programmed for 30 minute incubation period 161 of $32{ }^{\circ} \mathrm{C}$. After testing different extraction times (SPME headspace sampling times) that ranged 162 from 7 to 60 minutes, a method was developed using a 14 minute extraction time and 7 minute 163 SPME desorption time. The headspace extraction time was chosen to result in sufficient sensitivity 164 and also maintain the system in the linear, kinetically limited absorption range; i.e. not an 
165 equilibrium measurement. This was chosen because we anticipated that the target compounds were 166 present at a large fraction of their saturation concentration (in air and mixtures), and therefore, 167 there was a risk of non-linear absorption into the SPME coating. Similarly, a PDMS coating was 168 chosen because it operates primarily by absorption, which exhibits more linear partitioning 169 behavior at high-concentration conditions than coatings that are adsorptive. In determining the GC 170 desorption time, we performed repeated injections of the same fiber to experimentally confirm that 171 there was minimal carry-over (less than the limit of detection) of analytes to the following sample.

172 The measured relative fugacity of species $i, \dot{F}_{i}$, is defined as the GC-FID peak area for the cream 173 headspace sample, $F I D_{\text {cream }, i}$, divided by the headspace peak area for the pure compound, $F I D_{\text {pure }, i}$.

174 The fugacity is then defined as $F_{i}$ multiplied by the vapor pressure of the pure liquid species $i, P_{v, i}$ $175(\mathrm{~Pa})$, at that temperature. In the cream mixture, the liquid vapor pressure is necessary to calculate 176 relative fugacity. Since $\mathrm{BP}$ is a solid at $32{ }^{\circ} \mathrm{C}$, the relative fugacity is corrected by the ratio of the 177 predicted liquid and solid phase vapor pressures, $P_{v, B P, \text { liquid }}$ and $P_{v, B P, \text { solid }}$ :

$178 \quad \dot{F}_{B P}=\left(\frac{F I D_{\text {cream }, B P}}{F I D_{\text {pure }, B P}}\right)\left(\frac{P_{v, B P, \text { solid }}}{P_{v, B P, \text { liquid }}}\right)$

179 where ${ }^{69}$,

$180 \quad \frac{P_{v, B P, \text { solid }}}{P_{v, B P, \text { liquid }}}=-\frac{\Delta H_{f u s}}{R T_{m p}}\left(1-\frac{T_{m p}}{T}\right)$

$181 R$ is the gas constant $(8.314 \mathrm{~J} / \mathrm{mol} \mathrm{K})$, and the enthalpy of fusion, $\Delta H_{f u s}(26.3 \mathrm{~kJ} / \mathrm{mol})$ and melting 182 point temperature $T_{m p}(340 \mathrm{~K})$ are taken from Umnahant \& Chickos. ${ }^{70}$

184 We also compared the results to predictions resulting from the application of Raoult's law. We 185 applied Raoult's law to predict the relative fugacity, $F_{R, i}$, of the active chemicals assuming a well186 mixed mixture of the three compounds in the oily medium where there is no phase separation 187 among the organic/oily components and the activity coefficient is 1 . The oily fraction of the cream 188 was assumed to be 0.35 by weight, based on the mass change after drying the base cream in an 189 oven $\left(\sim 60^{\circ} \mathrm{C}\right)$. We also assumed no partitioning of the compounds into the water phase and that 190 the oily component of the cream is "petrolatum" or "trimethylbenzen[e]indole" with a molecular 
191 weight of $209 \mathrm{~g} / \mathrm{mol}$. The relative fugacity based on Raoult's law is given by the mole fraction of

192 chemical in a mixture containing equal masses of DEP, DnBP, BP and petrolatum while the mass

193 of cream change :

194

$\dot{F}_{R, i}=\frac{M_{i} / M W_{i}}{0.35 * M_{\text {cream }} / M W_{\text {petrolatum }}+{ }^{M_{D E P}} / M W_{D E P}+{ }^{M_{D n B P}} / M W_{D n B P}+{ }^{M_{B P}} / M W_{B P}}$

195 where $M_{i}$ is the mass of each component in the mixture and $M W_{i}$ is the molecular weight for 196 subscripted species $(\mathrm{g} / \mathrm{mol})$.

198 Only glass dishes, rods, and vials were used in all steps of sample preparation, mixing, and storage.

199 All of the glassware was washed and rinsed with methanol then dried in an oven at $150{ }^{\circ} \mathrm{C}$ prior

200 to use. The headspace was sampled using the same PDMS fiber throughout the experiments. The

201 SPME fiber was baked two to three times prior to headspace sampling. Vials of pure DEP, DnBP,

202 and BP were analyzed as SPME headspace references and as a regular check of the instrument

203 sensitivity. Analytical blanks were analyzed at the beginning and during the experiment (between

204 samples) to check for contamination and carry-over. No target compounds were observed in

205 headspace analysis of the undosed cream. Blank analysis showed no carry-over at low or mid

206 concentrations but there was a maximum carry-over of $0.45 \%$ of the prior injection of a high-

207 concentration DEP sample. Triplicate samples of each concentrations were prepared for headspace

208 SPME analysis. The limit of detection (LOD) and limit of quantification (LOQ) were determined

209 based on the average and standard deviation of replicates of blank samples. In order to calculate

210 LOD and LOQ, we converted the SPME signals to headspace concentration using the

211 measurement-based vapor pressure (see

212 Table 2) and the peak area of headspace samples over the pure compounds. Method LODs of 10,

21311 , and $21 \mu \mathrm{g} / \mathrm{m} 3$ and LOQs of 20, 22, and $50 \mu \mathrm{g} / \mathrm{m} 3$ were obtained for headspace gas

214 concentrations of DEP, DnBP, and BP, respectively. All concentrations of DEP and DnBP in both

215 single compound creams and mixture had signals higher than the LOD. The two lowest

216 concentrations of BP $(0.025$ and $0.074 \% \mathrm{~W} / \mathrm{W})$ in both single compound creams and mixture had

217 signals lower than the LOD. 
220 In the human subject study by Janjua et al., ${ }^{9} 26$ caucasian male participants were given a whole221 body treatment of a cream containing 2\% (w/w) of DEP, DnBP and BP once a day for 5 days. The 222 applied coverage was $2 \mathrm{mg} / \mathrm{cm}^{2}$ of cream and the average treatment area per subject was $2 \mathrm{~m}^{2}$. 223 They were told they could shower after 4 hours but the time interval between application and 224 showering was not recorded. All urine was collected and analyzed for metabolites of DEP (mono225 ethyl phthalate, MEP), DnBP (mono-butyl phthalate, MnBP) and BP. These compounds are present in urine in both free and conjugated forms (conjugation converts lipophilic compounds to

227 hydrophilic compounds which are more readily excreted) and samples were therefore treated 228 (deconjugated) to maximize quantification of uptake via excreted total mass. The average 24-h clearance of free and unconjugated metabolites in urine voids on the last day was $41.5 \mathrm{mg}, 12.5$ $\mathrm{mg}$ and $2.7 \mathrm{mg}$ for MEP, MnBP and BP respectively.

\subsubsection{Model framework}

232 The model by Morrison et al. ${ }^{59}$ was applied to simulate transdermal uptake of DEP, DnBP and BP 233 in human subjects described by Janjua et al. ${ }^{9}$ The simulation is applied to a "typical" subject, with 234 cream application in the morning, a shower later in the day (timing is varied in the simulation as 235 described below) and repeated for 5 days. Details of the parameters used in the model and the 236 simulation schedule are found in Supporting Information.

237 Morrison's model simulates dynamic transdermal uptake of chemicals assuming Fickian diffusion 238 through distinct physical layers of skin (skin lipids, startum corneum, and viable epidermis). In 239 this study, skin lipids were assumed to mix into the cream and the cream replaced the "skin oil" 240 layer in the Morrison et al. model. ${ }^{59}$ More detail on the model framework and the equations applied 241 can be found in Supporting Information. To directly use the measured fugacity in the model, we 242 assume the cream composition does not change upon whole-body application (due to immediate 243 evaporation of volatile ingredients or target compounds mixing with skin oil or sweat). However, 244 we do account for changes in the composition that are the result of absorption and evaporation of 245 target compounds. We also assume that the target compounds are at equilibrium throughout the 246 cream. This means that the chemical activity in different phases of an emulsion (if any) are equal 
247 and that the fugacity at the cream-skin interface is the same as that measured in vitro. The model 248 framework is equivalent to that of Cleek \& Bunge ${ }^{71}$ except that the compounds in the cream can 249 volatilize to air or transfer to clothing. The measured relative fugacity, and that predicted by 250 Raoult's law, of each chemical combined with the vapor pressure of the chemical at the 251 temperature of skin (see Model Parameters for values) was used to calculate the near skin gas 252 phase concentration of the chemical $\left(C_{g, i}\right)$.

$253 C_{g, i}=\frac{\dot{F}_{i} P_{v, i} M W_{i}}{R T}$

254 where, $M W i$ is the molecular weight of species $i$. Octanol/air partition coefficient of the chemical 255 was used to relate the $C_{g, i}$ to concentration of the chemical in skin lipids. After a subject showers, 256 the cream layer is set to a skin lipid layer of a defined thickness and the concentration of the target 257 chemical in this layer is set to zero. This skin lipid layer is allowed to equilibrate with the top layer 258 of the stratum corneum (SC) as well as the overlying air in the manner outlined Morrison et al. ${ }^{59}$ 259 That is, in the first time-step after a shower, the lipid layer concentration is set to zero, but the 260 concentration in the adjacent stratum corneum layer is not equal to zero. At the next time step, the 261 lipid layer accumulates chemicals from the stratum corneum to achieve equilibrium and also 262 equilibrates with the overlying air. For each chemical, the initial equilibrium air concentration, 263 adjacent to the cream, was calculated by multiplying the vapour pressure of the chemical by its 264 relative fugacity in the $2 \%$ mixture and converting to appropriate concentration units. In this 265 model, we assume that absorbed DEP, DnBP, and BP are rapidly metabolized; metabolites 266 accumulate in urine and are excreted with each urination. The model uses available experimental 267 toxicokinetic factors to compare the simulated excreted mass to the measured excreted mass of 268 Janjua human subject experiment data over the same time period. To make this comparison, we 269 apply toxicokinetic parameters determined by single oral dose methods for $\mathrm{BP}^{72}$ and $\mathrm{DnBP}^{73}$ for 270 different modes of action such as hydrolyzation, oxidation and/or conjugation. Assuming that the 271 metabolism of DEP is similar to that of DnBP, we set the DEP excretion fraction equal to that for 272 DnBP. Specifically, the amount of BP, MnBP and MEP excreted is equal to $0.056,0.84$ and 0.84 273 times the amount of BP, DnBP and DEP absorbed in the simulation, respectively. The model was 274 solved using a finite-difference approach in Microsoft Excel. 
276 Simulations are run for 120 hours starting with the whole-body cream application on the first day 277 and a shower later in the day; cream application and showering are repeated for 5 days to match 278 Janjua human subject study. Participants of the whole-body topical application in Janjua study 279 were asked to shower no sooner than 4 hours after the experiment, but the actual time between 280 application and showering was not recorded. ${ }^{9}$ Since the participants were treated at the same time 281 each day, we assumed a maximum of 20 hours between treatment and showering. Therefore, we 282 set the minimum and maximum time interval between application and showering to 4 and $20 \mathrm{~h}$, 283 respectively, and assigned a base-case value of 8 hours (8-hour scenario).

284 Base-case skin penetration parameters (see Table 2) required for the model were calculated based on the analyses and parameters discussed by Gong et al. ${ }^{74}$ and Morrison et al. ${ }^{59}$ Basic chemicalphysical properties of DEP, DnBP, and BP at $32^{\circ} \mathrm{C}$ (such as molecular weight $(\mathrm{g} / \mathrm{mol}$ ), density $\left(\mathrm{g} / \mathrm{cm}^{3}\right)$, molar volume $\left(\mathrm{cm}^{3} / \mathrm{mol}\right)$, and Henry's constant $\left(H_{c p}\right.$, atm $\left.\left.\mathrm{m}^{3} / \mathrm{mol}\right)\right)$ were obtained from SPARC online calculator (

292 Table 1) and were used to calculate other transdermal uptake model input parameters as follows 293 (See Supporting Information). The stratum corneum/air partition coefficient $\left(K_{s c-g}\right)$ for the partially 294 hydrated condition was based on previous methods, $3,74,75$ which primarily use the octanol/water 295 partition coefficient $\left(K_{o w}\right)$ and Henry's law constant $\left(H_{c p}\right)$ as input parameters. Equations derived 296 by Wang et al. ${ }^{76}$ were used to calculate the effective diffusion coefficient in partially hydrated 297 stratum corneum $\left(D_{s c}, \mathrm{~m}^{2} / \mathrm{s}\right)$. Equations in Appendix D of Dancik et al. ${ }^{77}$ were used to estimate 298 effective diffusion coefficients of chemicals in the viable epidermis $\left(D_{v e}, \mathrm{~m}^{2} / \mathrm{s}\right)$ and the viable 299 epidermis/water partition coefficient $\left(K_{v e-w}\right)$ and, finally, viable epidermis/air partition coefficient $300\left(K_{v e-g}\right)$. The stratum corneum's thickness $\left(L_{s c}\right)$ of $23 \mu \mathrm{m}$ and viable epidermis's thickness $\left(L_{v e}\right)$ of $301100 \mu \mathrm{m}$ were chosen based on the average skin layers' thicknesses measured and discussed in 302 previous papers. ${ }^{59,71,74,78-82}$ Discussion of the vapor pressure $\left(P_{v}\right)$ is found in the the Supporting 303 Information. A screenshot of the spreadsheet which was prepared for calculation of the transdermal 
304 uptake model input parameters is also found in the Supporting Information. The spreadsheet is 305 available from the authors upon request.

Table 1 Chemical-physical properties of DEP, DnBP, and BP at $32^{\circ} \mathrm{C}(303.15 \mathrm{~K})$

\begin{tabular}{|c|c|c|c|c|c|c|c|}
\hline compound & CAS & $\begin{array}{c}\text { MW } \\
(\mathrm{g} / \mathrm{mol})\end{array}$ & $\begin{array}{c}\text { Density } \\
(\mathrm{g} / \mathrm{cm} 3)\end{array}$ & $\begin{array}{c}\text { Volume } \\
(\mathrm{cm} 3 / \mathrm{mol})\end{array}$ & log (Kow) & $\begin{array}{c}\text { Hcp } \\
\mathrm{pa} \mathrm{m3/mol}\end{array}$ & $\begin{array}{c}P_{v} \\
\text { Pa }\end{array}$ \\
\hline DEP & $84-66-2$ & 222.2 & 1.13 & 197.3 & 2.55 & $8.83 \times 10^{-3}$ & 0.210 \\
\hline DnBP & $84-74-2$ & 278.3 & 1.05 & 266.1 & 4.56 & $2.49 \times 10^{-2}$ & 0.012 \\
\hline BP & $94-26-8$ & 194.2 & 1.08 & 179.7 & 3.39 & $8.05 \times 10^{-3}$ & $0.0036^{*}$ \\
\hline
\end{tabular}

*Vapor pressure of pure solid $\mathrm{BP}$

Table 2 Base-case and derived transdermal uptake model parameters at $32^{\circ} \mathrm{C}$ a

\begin{tabular}{|c|c|c|c|c|c|c|c|c|c|}
\hline compound & $\begin{array}{c}L_{s c} \\
(\mu \mathrm{m})\end{array}$ & $\begin{array}{c}L_{v e} \\
(\mu \mathrm{m})\end{array}$ & $K_{v e / w}$ & $K_{s s l / g}$ & $K_{s c / g}$ & $K_{v e / g}$ & $\begin{array}{c}D_{s c} \\
\mathrm{~m}^{2} / \mathrm{s}\end{array}$ & $\begin{array}{c}D_{v e} \\
\mathrm{~m}^{2} / \mathrm{s}\end{array}$ & $\begin{array}{c}h_{m} \\
\mathrm{~m} / \mathrm{h}\end{array}$ \\
\hline $\mathrm{DEP}$ & 23 & 100 & 2.19 & $1.0 \times 10^{8}$ & $7.1 \times 10^{6}$ & $6.3 \times 10^{5}$ & $2.4 \times 10^{-15}$ & $6.2 \times 10^{-11}$ & 25 \\
\hline $\mathrm{DnBP}$ & 23 & 100 & 32.6 & $3.7 \times 10^{9}$ & $2.7 \times 10^{7}$ & $3.3 \times 10^{6}$ & $4.0 \times 10^{-15}$ & $6.4 \times 10^{-12}$ & 25 \\
\hline $\mathrm{BP}$ & 23 & 100 & 5.25 & $7.7 \times 10^{8}$ & $1.8 \times 10^{7}$ & $1.7 \times 10^{6}$ & $8.3 \times 10^{-15}$ & $3.2 \times 10^{-11}$ & 25 \\
\hline
\end{tabular}

314 a Method details and all other supporting parameters can be found in Supporting Information

315 The average body surface area of $2 \mathrm{~m}^{2}$ was obtained from Janjua human subject study. ${ }^{9}$ The cream 316 thickness of $20 \mu \mathrm{m}$ was calculated based on the mass of cream which was used in Janjua human 317 subject study for each participant and the assumption of cream density equal to $1 \mathrm{~g} / \mathrm{cm}^{3}$. The skin 318 lipid thickness, after showering, is set to $1.2 \mu \mathrm{m}$. The gas-side mass transfer coefficient, $h_{m}$, was 319 set to $25 \mathrm{~m} / \mathrm{h}$, reflecting a high value associated with wearing clothing after application of the 320 cream. ${ }^{82}$ We do not consider transfer of cream to clothing. If some of the cream has transferred to 321 clothing, it is still "near" the skin and we assume it is effectively "on" the skin. However, ignoring 322 transfer onto clothing could result in an overestimate of transdermal uptake, since there may be an 323 increased mass-transfer resistance between cream (on clothing) and the stratum corneum. 
325 To make a direct comparison of the Janjua human subject study ${ }^{9}$ to the model, the raw urine 326 concentration results were converted to a mass-rate of excretion. Total excretion mass (free + 327 unconjugated metabolite) per hour for each participant at each urine sample collection time is

$328 \quad \dot{M}_{\text {total }}=\frac{V C}{t}$

329 where $\dot{M}_{\text {total }}$ is the total excretion mass per hour $(\mu \mathrm{g} / \mathrm{h}), V$ is the urine sample volume $(\mathrm{ml}), C$ is 330 the concentration of the metabolite of the chemical in the urine sample $(\mu \mathrm{g} / \mathrm{ml})$, and $t$ is the time 331 interval between the previous and current urine sample (h).

332 The urination time obtained from Janjua human subject study was used to plot minimum, mean \pm 333 standard deviation, and maximum of excretion rates for all subjects at each time point between 0 334 to 120 hours after the start of the experiment. Model excretion rate was calculated based on a 335 urination frequency of every 5 hours during the first $24 \mathrm{~h}$; after that, the model results are reported 336 as $24 \mathrm{~h}$ pooled urine samples to be consistent with Janjua human subject study. ${ }^{9}$ Modeled excretion 337 rates of metabolites were adjusted by the toxicokinetic excretion ratios (see section 2.6.2) and 338 molecular weights.

\subsubsection{Sensitivity analysis}

In addition to the base-case values (

341 Table 2) the influence of stratum corneum thickness, shower time, skin temperature, vapor 342 pressure, and partition coefficients were evaluated. The stratum corneum thickness $\left(L_{s c}\right)$ not only 343 varies with age, sex, skin health status (for example eczema), but also varies among different parts 344 of the body and can depend on skin hydration. We used lower and upper values of 15 and $30 \mu \mathrm{m}$ 345 for $L_{s c} .59,71,79,81 \mathrm{We}$ also evaluated the effect of elapsed time between the cream application and 346 showering (4-20 hours). Like the stratum corneum thickness, skin temperature also varies with sex 347 age, body mass index (BMI), percent of body fat (PBF), and skeletal muscle mass (SMM). ${ }^{83,84}$ 348 Studies also have measured different skin temperatures for different parts of the body. ${ }^{83}$ In addition 349 to endogenous factors, skin temperature is influenced by the surrounding environment such as air 350 temperature, wind, and humidity. ${ }^{85} \mathrm{~A}$ wide range of skin temperatures have been observed for 351 different body locations for female and male subjects at moderate and severe environmental 
352 conditions. ${ }^{85-87} \mathrm{We}$ chose a skin temperature range of $25-37{ }^{\circ} \mathrm{C}$ for the sensitivity analysis. To

353 evaluate the influence of vapor pressure, we set the upper and lower bounds to be twice and half

354 the model base-case values; respectively. To evaluate the influence of partition coefficients, we 355 assumed half and double of the base-case partition coefficients, and we assumed diffusion 356 coefficients vary inversely with the partition coefficients. ${ }^{59}$

3. Results and Discussion

Figure 1 visualizes the results of SPME headspace analysis of each single-component creams and three-component creams for DEP, DnBP, and BP. Results are reported as the peak area of the chemical in the mixture normalized by the peak area of the pure compound (relative fugacity, $F_{i}$ ) vs the mass fraction of the compound in the mixture. In addition to the experimental data, each chemical's relative fugacity, as predicted by Raoult's law (Equation 3), has been added to each plot. This curve illustrates the relative fugacity of each compound assuming a homogeneous solution of the three compounds in the petrolatum of the cream. There are four main observations from these results. First, for either the single-component creams or three-component creams, the relative fugacity is greater than the weight fraction of the component in the cream. For example, $F_{i}$ for a $2 \%(\mathrm{w} / \mathrm{w})$ mixture is greater than $2 \%$ of the pure chemical's headspace peak area. For the single component mixtures, each at $2 \%$ by weight, $F_{i}$ of DEP, DnBP, and BP are $0.72,0.37$, and 0.46, respectively. Second, for a given mass fraction in the cream, the relative fugacity of each chemical is greater in a single-component cream than in the three-component cream. For the threecomponent mixture, each at $2 \%$ by weight, $F_{i}$ of DEP, DnBP, and BP are $0.33,0.14$, and 0.30 ; respectively. This suggest that the additional lipophilic mass fraction of the active ingredients $(\mathrm{DEP}+\mathrm{DnBP}+\mathrm{BP})$ suppresses the vapor pressure of each compound. Third, these values are mostly greater than the relative fugacity based on an application of Raoult's law for mixtures of the three compounds in the oily medium of cream. The Raoult-based estimate approaches (or crosses) the measured results at the highest cream concentration. Extrapolating the data to the point where only the three chemicals are present (each representing $1 / 3$ of the mixture without base cream), the fugacity appears to be reasonably predicted by Raoult's law (where the curve ends at the right side 
381 non-linear. These results show that $F_{i}$ in the cream may not be predicted solely from Raoult's law. 382 It may be possible to apply Henry's law at the lower concentration range, as demonstrated recently 383 for mixtures of oil soluble solutes in an oily medium. ${ }^{88}$ However, the data in our study are 384 insufficient to demonstrate linearity in the low concentration range. A version of Figure 1 with 385 linear axes can be found in Supporting Information.
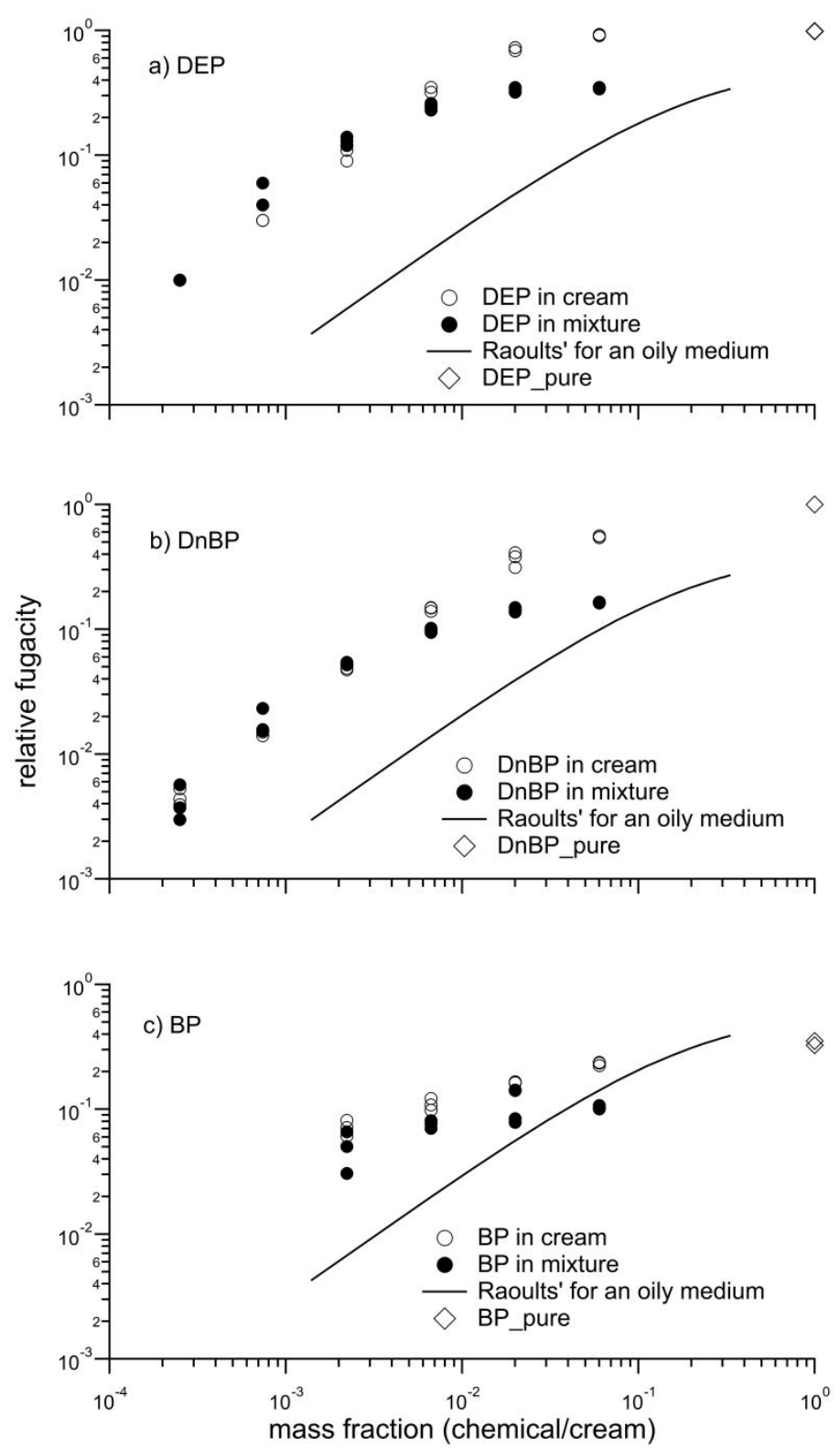

387 Figure 1. Measured relative fugacity, $F_{i}$, (normalized SPME signals) vs. mass fraction of each chemical in single-component creams $388(\bigcirc)$ and in three-component creams $(\bullet)$. The diamond symbol $(\diamond)$ represents the result for the pure chemical without cream. Also 389 shown is the relative fugacity prediction based on Raoults' law of the three chemicals in a well-mixed lipophilic fraction of the 
cream (solid line). All BP results shown have been adjusted to account for the fact that the pure BP reference is solid at room temperature.

\subsection{Model results}

394 Figure 2 compares the results of excretion rates for each chemical from Janjua human subject data ${ }^{9}$ 395 and the dynamic transdermal uptake simulation, using the base-case parameters (Table 2). Two 396 simulations are shown for different time intervals between cream application and showering: an 397 8-h scenario and a 4-h scenario. Data from Janjua's human subject experiment is reported as the 398 mean, plus-or-minus one standard deviation (SD), minimum and maximum. Dynamic simulations 399 of excretion are qualitatively similar to the results of the human subject experiment. For the 8-h 400 scenario, the simulated BP excretion rate after 1 day is within plus-or-minus one standard deviation 401 of the human subject excretion rate. The simulated excretion rate for MEP and MnBP for the 8-h 402 scenario is higher, but still within a factor of 3 of that for human subjects. The 8-h scenario 403 simulations result in excretion rates that are almost twice that assuming a shorter, 4-h scenario; the 404 amount absorbed and excreted is very sensitive to showering time. A comparison of the 24-h 405 cumulative excretion after $120 \mathrm{~h}$ is shown in Figure S3 of Supporting Information for Janjua 406 human subject experiment data, the model using measured relative fugacity and the model using 407 the estimated relative fugacity based on Raoult's law (see section 2.4). The Raoult's law based 408 predictions are closer to the human subject experiment than those based on measured fugacity for 409 DEP and DnBP, but not BP (Supporting Information).

410 Similar to the results of Janjua human subject study, the simulation also predicts an increase in the 411 excretion rate of MEP, MnBP and BP very soon after topical application. In both data obtained 412 from the human experiment and in the simulation, the concentration of all chemicals peaked in 413 urine 8-12 hours after whole-body application. Both the human experiment and simulation show 414 higher absorption of DEP than the other two chemicals, which is consistent with its chemical 415 properties. 

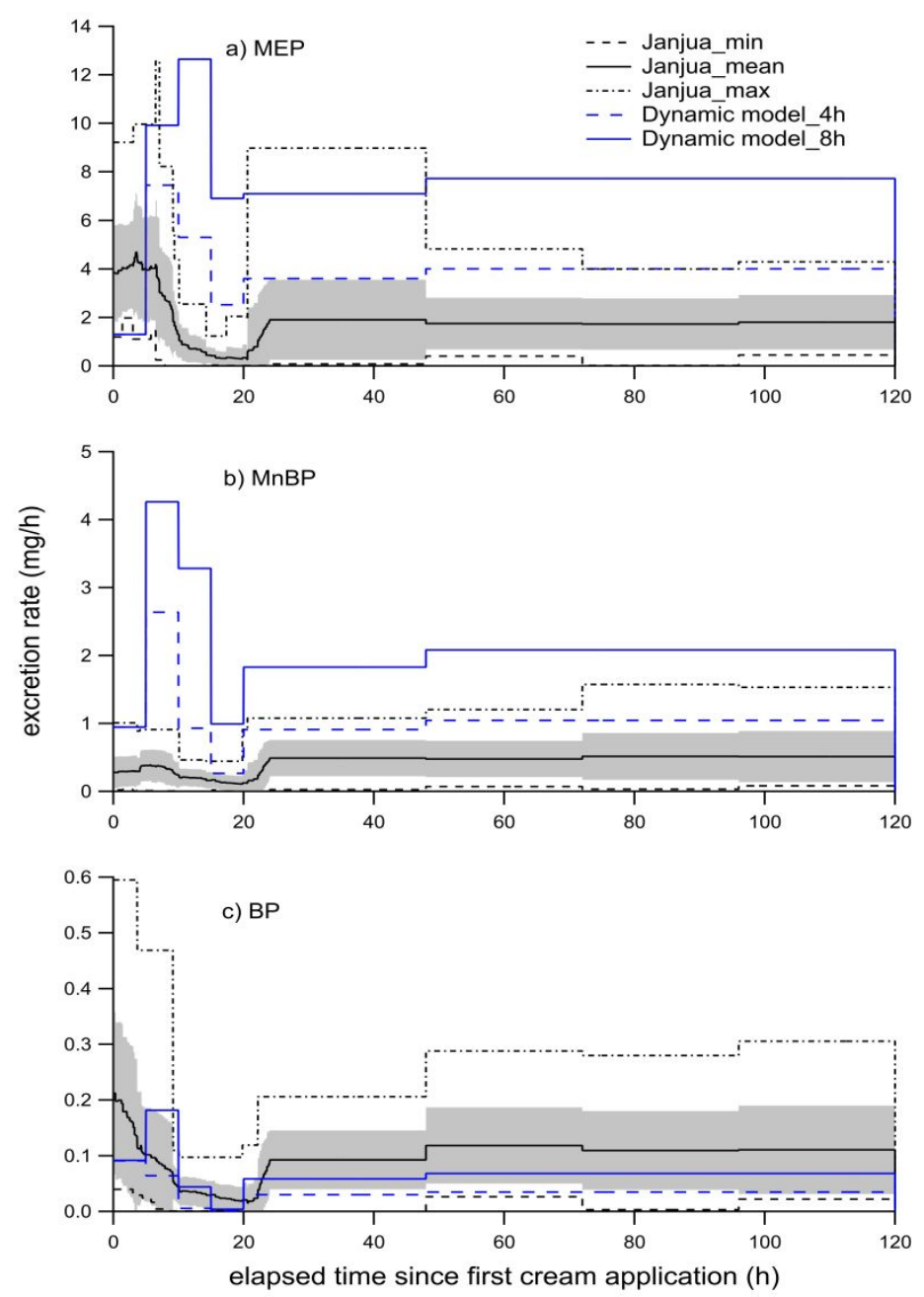

418 Figure 2 Excretion rates of metabolites for a) BP-, b) DnBP and c) DEP. Shown in grey and black are the combined results from 26 human subjects in Janjua study. ${ }^{9}$ Grey shaded region represents \pm one standard deviation. The blue solid line is the model output using an 8-h shower interval; the blue dashed line represents the model using a 4-h shower interval.

423 Some insight into the differences between model analysis and human subject results can be 424 obtained by comparing shapes of the dynamic cumulative uptake figures. Shown in Figure 3 is a 425 comparison of the predicted and measured cumulative urinary excretion of metabolites for the first $42624 \mathrm{~h}$ after the initial topical application. We only show the excretion data of the individuals with 427 at least seven urinations during the first $24 \mathrm{~h}$. The predicted cumulative urinary excretion is shown 428 for elapsed times of 4, 8, and $20 \mathrm{~h}$ between the topical application and showering. Qualitatively, 429 showering later lengthens the time over which cumulative uptake occurs, as anticipated. For a 4-h 430 scenario, the accumulation begins to flatten out by about 8 to $12 \mathrm{~h}$. For a 20 -h scenario, uptake 
431 increases during the whole period. Similar shapes can be discerned in the human subject data. 432 Early flattening of the curve, among all metabolites, for subject P9 may indicate an early shower. 433 The monotonic increase in excretion of MnBP and BP, exhibited by subject P22, may suggest a 434 late shower or poor removal of the cream during an earlier shower.

435 There is an inconsistency in the relative shapes of the modeled and measured curves. For MEP, 436 the cumulative excretion curves of the human subject flatten out sharply between 6 and $12 \mathrm{~h}$. For $437 \mathrm{BP}$, this occurs later and less sharply. MnBP generally rises throughout the period with only a 438 modest flattening. These trends differ from those predicted by the model. It may be that during the 439 experiments the participants were more exposed to DnBP from additional sources compared with 440 DEP and BP. If this is not the case, this disagreement between measured and modeled results may 441 indicate that diffusivity predictions are inaccurate (even relative to one another). Diffusivity 442 predictions are further discussed in Section 3.4.

443 Another inconsistency is the lag time in the model compared to a fast increase in cumulative 444 urinary excretions of the human experiment data (mainly for MEP). This may be due to early 445 uptake through the hair follicles pathway resulting in a rapid rise of urinary metabolites; this 446 mechanism is also discussed in more detail in Section 3.4. 

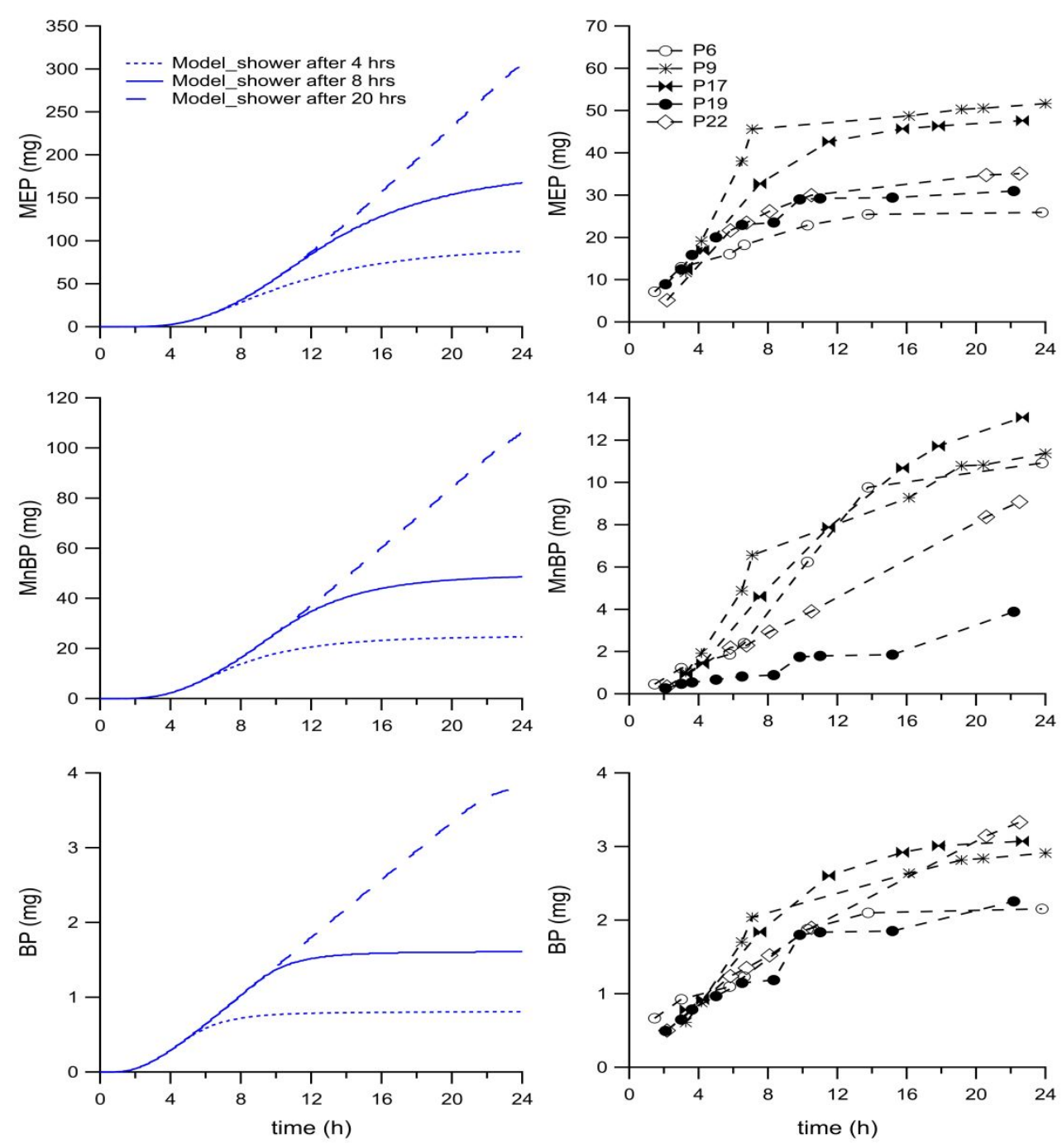

Figure 3 Estimated (graphs on left) and measured (graphs on right) cumulative urinary excretion of monoethyl phthalate (MEP), mono-n-butyl phthalate (MnBP), and butyl paraben (BP) within the first $24 \mathrm{~h}$ after the initial topical application of the cream.

\subsection{Sensitivity analysis}

451 To study the effects of model input uncertainties, Figure 4 compares the transdermal uptake model 452 outputs (total steady state excretion mass) for a range of vapor pressure, shower times, stratum 453 corneum thicknesses, and skin temperatures. The dashed lines show the total excretion mass of the 454 chemicals using the base-case parameters. Figure 4 also compares the predictions with the range 455 of excretion values of the 26 participants in Janjua study. ${ }^{9}$ The simulations for BP are consistent 456 with the experimental results. For DEP and DnBP, use of base-case input parameters results in 457 predictions that are greater than mean values from human subjects; however, use of a reasonable 458 range of values (as defined in section 2.6.5) for vapor pressure, showering time, stratum corneum 
thickness and skin temperature result in some predictions that are within the range of the human subject excretion mass for MnBP and MEP. Excretion mass is directly proportional, and therefore very sensitive, to the choice of vapor pressure.
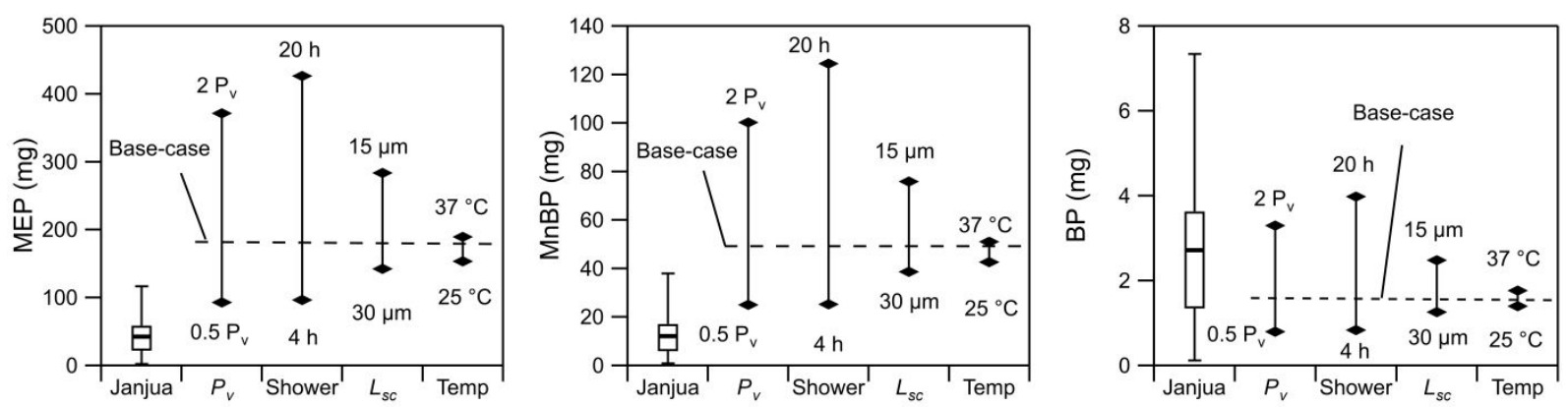

462

463

464

465

466

467

468

469

470

471

472

473

474

475

Figure 4 Sensitivity of transdermal uptake model predictions of excretion mass to vapor pressure $\left(P_{v}\right)$, showering time, stratum corneum thickness $\left(L_{s c}\right)$ and skin temperature (Temp). For the Janjua human subject experiment, the line is the mean, the box is the upper and lower quartile (Q1 and Q3), and the whiskers are the maximum and minimum values.

The predicted excretion mass is also very sensitive to the time between cream application and showering, with the excretion mass increasing nearly linearly with the time before showering. The excretion mass of the chemicals using a stratum corneum thickness of $15 \mu \mathrm{m}$ is almost twice the mass using a thickness of $30 \mu \mathrm{m}$. Changing the partition coefficients did not result in significant changes in the model output (this is not shown in Figure 4); to be internally consistent with the methods used to determine skin parameters, doubling a partition coefficient results in halving the diffusivity, which in turn, results in a nearly constant permeability. However, changing the partition coefficient (e.g. Ksc) without altering the diffusivity, or vice versa, would strongly influence uptake. For example, doubling either Ksc or Dsc nearly doubles the mass absorbed.

Excretion mass increases with temperature, but only by a modest amount. In our model, this is because as temperature increases, the predicted chemical driving force (fugacity) increases while the stratum corneum-air partition coefficient, $K_{s c-g}$, decreases. For example, as temperature rises from 25 to $37^{\circ} \mathrm{C}$, the fugacity of DnBP increases by a factor of 4.8 but $K_{s c-g}$ decreases by about a factor of 3.4 (see Table S3, S4, S5). There is a slight increase in diffusivity of DnBP: $3.91 \times 10^{-15}$ to $4.11 \times 10^{-15} \mathrm{~m}^{2} / \mathrm{s}$. In combination, the resulting steady-state flux increases by about $22 \%$. This result may seem inconsistent with in-vitro studies that show permeability increasing with more substantially over the same temperature range. ${ }^{89-94}$ For many in-vitro studies, the permeability is based on the concentration in the vehicle at the saturation concentration of the permeant. Over a 
484 small temperature range, the concentration in the vehicle only changes slightly, for hydrophobic 485 compounds. As an example, Akomeah et al..$^{92}$ observed that the saturation concentration of BP in an aqueous vehicle increased by about $20 \%$ from $23^{\circ} \mathrm{C}$ to $30^{\circ} \mathrm{C}$. However, they do not account for

487 the higher chemical activity or fugacity that would result at the higher temperature; we predict the 488 fugacity of BP in their vehicle would have increased by nearly a factor of 3, accounting for much 489 of the increase in observed permeability. That said, a major assumption in our model is that the 490 relative fugacity of each component in the cream is not itself influenced by temperature; given the 491 good match with Raoult's law for a high-concentration cream, this seems to be a reasonable 492 assumption. But this assumption could also result in an over-prediction of fugacity for a complex 493 solution at a lower temperature. Such qualitative differences in modeled vs experimental 494 observations should be investigated more thoroughly.

495 Figure 2 shows that the dynamic simulations of excretion rate, that are based on fugacity 496 measurements of cream, are qualitatively similar to the results for the human subjects, but are 497 higher in magnitude for DEP and DnBP. The model, using base-case values, overestimated 498 transdermal uptake of DEP and DnBP for even the human subject that had the highest apparent 499 uptake (Figure 4). Quantitative deviations between the results of Janjua human subject experiment 500 and our predictions may be due the model framework or, as demonstrated by the sensitivity 501 analysis, the choice of parameters used to populate the model. In particular, vapor pressure and 502 showering time are influential, but uncertain, variables. Further, we base our toxicokinetic factor 503 on oral ingestion for all chemicals; better would be to apply a toxicokinetic factor based on skin 504 absorption but this value has not, to our knowledge, been reported. We have no basis for setting 505 upper and lower bounds on this value in the sensitivity analysis, but if the toxicokinetic factor is, 506 for example, 20\% lower for skin absorption than for oral ingestion, then the excretion rate would 507 also be $20 \%$ lower since the excretion rate is linearly dependent on the toxicokinetic factor.

508 Skin temperature may have a bigger impact than we have shown. To estimate transdermal uptake 509 of the active chemicals at different skin temperatures, we only rely on vapor pressure, diffusivities, 510 and partition coefficients. In other words, we do not consider changes in the skin physiology such 511 as changes in stratum corneum lipid structure and changes in effective diffusion length due to 512 changes in skin temperature or skin hydration. ${ }^{95-97}$ 
513 In our transdermal uptake estimation, we assumed the cream composition does not change as a 514 result of the whole-body application and mixing with skin oil. This assumption allows us to use 515 our measured fugacity directly in the model. Both the model and the Janjua human subject 516 experiment ${ }^{9}$ show that only a small fraction of the compound are absorbed from the cream. This 517 is considered a "high load" condition in which the load applied (mass per area) does not influence 518 the rate of transdermal uptake. Increasing the amount of cream applied would not have increased 519 metabolite excretion. Although we account for loss of target chemicals from the cream by 520 absorption, the fact that the composition changes little, in a sense, simplifies the comparison 521 because only fugacity and permeability are important. This is the advantage of using fugacity in 522 transdermal uptake risk assessment over fixed absorption dose which depends on the load or mass 523 amount of test chemical applied to the skin..$^{98-100}$ It is possible that fugacity may change after 524 application as, for example, water or other volatile ingredients evaporate from the applied cream. 525 For the high-concentration cream used in Janjua et al., ${ }^{9}$ this probably does not alter fugacity very 526 much since gas-phase fugacity appears to be dominated by the fugacity of the three-component 527 mixture, not the amount of base cream. However, as volatiles evaporate from a low-concentration 528 cream, the active ingredients become more concentrated in the low-volatility oily components of 529 the cream resulting in an altered, or perhaps even increased, fugacity. This suggests that future 530 experiments should include in vivo measurement of fugacities after cream application to volunteer 531 skin.

532 We also assumed that the target compounds are at equilibrium throughout the cream. If the cream 533 is comprised of multiple phases (e.g. an emulsion) this may result in phase separation upon 534 application to skin; more likely the oily components would preferentially mix with skin lipids. If 535 the fugacity is not equal among phases, this would result in a different driving force at the cream536 skin interface. However, a well-mixed cream with a large surface area between phases will come 537 to equilibrium rapidly and the fugacity will be equal among phases, even if the oily phase would 538 necessarily have a much higher concentration of lipophilic compounds. This means that the 539 fugacity at the cream-skin interface would be the same as that measured in vitro even if the oily 540 phase preferentially contacts the skin.

541 Skin hydration can significantly affect estimated transdermal uptakes, because an increase in the 542 water content of the stratum corneum can alter partitioning and diffusivity. An increase in water 
543 content can also result in an increase in stratum corneum thickness. ${ }^{76}$ It has been observed in 544 several in vivo and in vitro experiments that increases in skin hydration can lead to an increase in 545 permeability of stratum corneum which could be the result of an increase in the fluid fraction of 546 SC proteins and lipids. ${ }^{101-104}$ At higher skin hydration, a higher flux of both hydrophilic and 547 lipophilic compounds have been observed. ${ }^{101,102,105,106}$ Spencer et al. ${ }^{107}$ measured a maximum 60\% 548 increase in stratum corneum thickness after skin was exposed to water for 60 minutes. Lotion and 549 moisturizers can change skin hydration. ${ }^{108,109}$ However, changes in skin hydration and stratum 550 corneum thickness generally do not occur when applying lotions and moisturizers over short time 551 intervals. ${ }^{108,109}$ Therefore, we feel comfortable with our assumption that the skin in the Janjua 552 human subject experiment was "partially hydrated" and that the hydration condition was not 553 significantly altered by cream application.

554 Penetration through the skin-folicle pathway may be the reason Janjua observed a fast increase in 555 cumulative urinary excretion of target chemicals, most notably MEP, immediately after topical 556 application of the creams in human subjects. Unlike a longer delay in absorption of chemicals from 557 the stratum corneum, penetration through hair follicles occurs immediately after topical 558 application. ${ }^{110}$ Frum et al. ${ }^{111}$ showed that hair follicles are responsible for 34 to $60 \%$ of the 559 penetration of chemicals (drugs) with intermediate and low octanol/water partition coefficients. 560 However, they only contributed in 2 to $4 \%$ of transdermal uptake for more lipophilic molecules. 561 DEP, DnBP, and BP are all lipophilic; DEP is the least lipophilic with an octanol/water partition 562 coefficient about 100 and 7 times lower than DnBP and BP at $32{ }^{\circ} \mathrm{C}$; respectively. Since our model 563 only considers the stratum corneum pathway, the simulations do not capture this early rise in 564 excretion rates (Figure 3). However, since most of the permeation occurs via the stratum corneum, 565 the cumulative uptake is reasonably captured by the model.

\section{4. Implications}

567 In this paper, we show that dynamic simulations based on fugacity measurements of two phthalates 568 and a paraben mixed in a cream are consistent with the results of human experiments conducted 569 by Janjua et al. ${ }^{9}$ This supports the general principal that the concept of fugacity can be used to 570 quantitatively estimate transdermal exposure from contact with environmental media. Cosmetics 571 can serve as a valuable proxy for environmental media that allows for control of composition and 
572 precise measurements of uptake and excretion in human subjects. There exist many other in vivo 573 or in vitro measurements of transdermal uptake reported in the cosmetic and pharmaceutical 574 literature that can be used to test models of uptake from environmental media. This may be 575 especially valuable for exposure to substances present at relatively high concentrations, such as 576 chemicals in paint, ${ }^{112}$ PVC flooring, ${ }^{113,114}$ or from occupational exposures. ${ }^{115}$ Our results also 577 support the use of fugacity instead of fixed absorption dose in transdermal uptake risk assessment. 578 However, models like this must be used with caution since quantitative predictions are very 579 sensitive to the choice of model parameters such as vapor pressure, diffusion coefficients, stratum 580 corneum thickness, defective skin barrier function, skin temperature, and elapsed time between 581 topical application and shower time. Despite these current limitations, we believe that the 582 measured fugacity is a valuable tool for estimating exposure, dose and risk of chemicals in cosmetic products and environmental media.

584 We also show that the relationship between measured fugacity and cream composition is highly 585 non-linear and even as low as $0.2 \%$ in solution, the solute exhibits non-ideal behavior. At low 586 concentrations, linear extrapolation may be acceptable. Therefore, extrapolation from in vivo data 587 at one concentration cannot be used to predict uptake and excretion at other concentrations for 588 complex mixtures like cosmetics and personal care products with high solute concentrations of 589 active ingredients. For exposure and risk assessment, linear extrapolation or fixed-absorption dose 590 methods must be used with caution for such mixtues or other materials in contact with skin (e.g., 591 clothing). For many chemicals in personal care products, we believe the application of the 592 measured relative fugacity is superior to these dose-estimation methods: it is easy to measure and 593 can be directly included in fundamental models of mass transfer through skin that make reasonable 594 predictions of transdermal uptake.

\section{ACKNOWLEDGEMENTS}

596 The authors would like to thank the Center for Research in Energy and the Environment (CREE) 597 of the Missouri University of Science \& Technology for their help with the instruments. Thanks 598 to Dr. Nadeem Janjua for generating the original experimental results from human participants and 599 providing access to the de-identified raw data. We also thank Dr. Gabriel Bekö for valuable 600 conversations and facilitating contact with Hanne Frederiksen. 
601

602

603

604

605

606

607

608

609

610

611

612

613

614

615

616

617

618

619

620

621

622

623

624

625

626

627

Supporting Information Available

- Vapor pressures of DEP, DnBP, and BP. Linear version of relative measured fugacity vs mass fraction of each chemical in cream mixtures. Description of the transdermal uptake model used in this study. Calculations of transdermal uptake model input parameters and the parameters at temperature ranges between $25-37^{\circ} \mathrm{C}$.

\section{REFERENCES}

(1) Hwang, H. M.; Park, E. K.; Young, T. M.; Hammock, B. D. Occurrence of EndocrineDisrupting Chemicals in Indoor Dust. Sci. Total Environ. 2008, 404 (1), 26-35. https://doi.org/10.1016/j.scitotenv.2008.05.031.

(2) Rudel, R. A.; Dodson, R. E.; Perovich, L. J.; Morello-Frosch, R.; Camann, D. E.; Zuniga, M. M.; Yau, A. Y.; Just, A. C.; Brody, J. G. Semivolatile Endocrine-Disrupting Compounds in Paired Indoor and Outdoor Air in Two Northern California Communities. Environ. Sci. Technol. 2010, 44 (17), 6583-6590. https://doi.org/10.1021/es100159c.

(3) Weschler, C. J.; Nazaroff, W. W. Semivolatile Organic Compounds in Indoor Environments. Atmos. Environ. 2008, $42 \quad$ (40), 9018-9040. https://doi.org/10.1016/j.atmosenv.2008.09.052.

(4) Weschler, C. J.; Nazaroff, W. W. SVOC Exposure Indoors: Fresh Look at Dermal Pathways. Indoor Air 2012, 22 (5), 356-377. https://doi.org/10.1111/j.16000668.2012.00772.x.

(5) Lucattini, L.; Poma, G.; Covaci, A.; de Boer, J.; Lamoree, M. H.; Leonards, P. E. G. A Review of Semi-Volatile Organic Compounds (SVOCs) in the Indoor Environment: Occurrence in Consumer Products, Indoor Air and Dust. Chemosphere. Elsevier Ltd June 1, 2018, pp 466-482. https://doi.org/10.1016/j.chemosphere.2018.02.161.

(6) Weschler, C. J.; Bekö, G.; Koch, H. M.; Salthammer, T.; Schripp, T.; Toftum, J.; Clausen, G. Transdermal Uptake of Diethyl Phthalate and Di(n-Butyl) Phthalate Directly from Air: Experimental Verification. Environ. Health Perspect. 2015, 123 (10), 928-934. https://doi.org/10.1289/ehp.1409151. 
628 (7) Janjua, N. R.; Mogensen, B.; Andersson, A.-M.; Petersen, J. H.; Henriksen, M.; Skakkebæk, N. E.; Wulf, H. C. Systemic Absorption of the Sunscreens Benzophenone-3, OctylMethoxycinnamate, and 3-(4-Methyl-Benzylidene) Camphor After Whole-Body Topical Application and Reproductive Hormone Levels in Humans. J. Invest. Dermatol. 2004, 123 (1), 57-61. https://doi.org/10.1111/j.0022-202X.2004.22725.x.

Janjua, N. R.; Mortensen, G. K.; Andersson, A. M.; Kongshoj, B.; Skakkebæk, N. E.; Wulf, H. C. Systemic Uptake of Diethyl Phthalate, Dibutyl Phthalate, and Butyl Paraben Following Whole-Body Topical Application and Reproductive and Thyroid Hormone Levels in Humans. Environ. Sci. Technol. 2007, 41 (15), 5564-5570. https://doi.org/10.1021/es0628755.

(9) Janjua, N. R.; Frederiksen, H.; Skakkebæk, N. E.; Wulf, H. C.; Andersson, A.-M. Urinary Excretion of Phthalates and Paraben after Repeated Whole-Body Topical Application in Humans. Int. J. Androl. 2008, 31 (2), 118-130. https://doi.org/10.1111/j.13652605.2007.00841.x.

(10) Janjua, N. R.; Kongshoj, B.; Andersson, A. M.; Wulf, H. C. Sunscreens in Human Plasma and Urine after Repeated Whole-Body Topical Application. J. Eur. Acad. Dermatology Venereol. 2008, 22 (4), 456-461. https://doi.org/10.1111/j.1468-3083.2007.02492.x.

(11) Zhang, X. X.; Yu, Y. Y.; Gu, Y.; Li, X.; Zhang, X. X.; Yu, Y. Y. In Vitro Determination of Transdermal Permeation of Synthetic Musks and Estimated Dermal Uptake through Usage of Personal Care Products. Chemosphere 2017, 173, 417-424. https://doi.org/10.1016/j.chemosphere.2017.01.001.

(12) Brown, S. L.; Rossi, J. E. A Simple Method for Estimating Dermal Absorption of Chemicals in Water. Chemosphere 1989, 19 (12), 1989-2001. https://doi.org/10.1016/00456535(89)90022-2.

652 (13) Lewis, G. N. The Law of Physico-Chemical Change. Proc. Am. Acad. Arts Sci. 1901, 37 653 (3), 49. https://doi.org/10.2307/20021635. 
Arts Sci. 1907, 43 (7), 259-293. https://doi.org/10.2307/20022322.

656

657

658

659

660

661

662

663

664

665

666

667

668

669

670

671

672

673

674

675

676

677

678

679

680

(15) Prausnitz, J. M. Molecular Thermodynamics of Fluid-Phase Equilibria; Prentice-Hall: Englewood Cliffs N.J., 1969.

(16) Zhou, C.; Hall, F.; Gasem, K. A. M.; Robinson, R. L. Predicting Gas Adsorption Using Two-Dimensional Equations of State; 1994; Vol. 33. https://doi.org/10.1021/ie00029a026.

(17) Dias, T. P. V. B.; Fonseca, L. A. A. P.; Ruiz, M. C.; Batista, F. R. M.; Batista, E. A. C.; Meirelles, A. J. A. Vapor-Liquid Equilibrium of Mixtures Containing the Following Higher Alcohols: 2-Propanol, 2-Methyl-1-Propanol, and 3-Methyl-1-Butanol. J. Chem. Eng. Data 2014, 59 (3), 659-665. https://doi.org/10.1021/je400581e.

(18) Khoshsima, A.; Dehghani, M. R. Phase Behavior of Glycol Ether Surfactant Systems in the Presence of Brine and Hydrocarbon: Experiment and Modeling. Fluid Phase Equilib. 2016, 414, 101-110. https://doi.org/10.1016/j.fluid.2016.01.019.

(19) Bohloul, M. R.; Arab Sadeghabadi, M.; Peyghambarzadeh, S. M.; Dehghani, M. R. CO2 Absorption Using Aqueous Solution of Potassium Carbonate: Experimental Measurement and Thermodynamic Modeling. Fluid Phase Equilib. 2017, 447, 132-141. https://doi.org/10.1016/j.fluid.2017.05.023.

(20) Tomba, J. P. Understanding Chemical Equilibrium: The Role of Gas Phases and Mixing Contributions in the Minimum of Free Energy Plots. J. Chem. Educ. 2017, 94 (3), 327-334. https://doi.org/10.1021/acs.jchemed.6b00726.

(21) Ferguson, J. The Use of Chemical Potentials as Indices of Toxicity. Proc. R. Soc. B Biol. Sci. 1939, 127 (848), 387-404. https://doi.org/10.1098/rspb.1939.0030.

(22) Mackay, D. Finding Fugacity Feasible. Environ. Sci. Technol. 1979, 13 (10), 1218-1223. https://doi.org/10.1021/es60158a003.

(23) McKone, T. E.; Howd, R. A. Estimating Dermal Uptake of Nonionic Organic Chemicals from Water and Soil: I. Unified Fugacity-Based Models for Risk Assessments. Risk Anal. 1992, 12 (4), 543-557. https://doi.org/10.1111/j.1539-6924.1992.tb00711.x. 
681

682

683

684

685

686

687

688

689

690

691

692

693

694

695

696

697

698

699

700

701

702

703

704

705

706

707

(24) Webster, E.; Mackay, D.; Qiang, K. Equilibrium Lipid Partitioning Concentrations as a Multi-Media Synoptic Indicator of Contaminant Levels and Trends in Aquatic Ecosystems. J. Great Lakes Res. 1999, 25 (2), 318-329. https://doi.org/10.1016/S0380-1330(99)707409.

(25) Trapp, S.; Franco, A.; MacKay, D. Activity-Based Concept for Transport and Partitioning of Ionizing Organics. Environ. Sci. Technol. 2010, 44 (16), 6123-6129. https://doi.org/10.1021/es100509x.

(26) Williams, P. R. D.; Sahmel, J.; Knutsen, J.; Spencer, J.; Bunge, A. L. Dermal Absorption of Benzene in Occupational Settings: Estimating Flux and Applications for Risk Assessment. Crit. Rev. Toxicol. 2011, $41 \quad$ (2), 111-141. https://doi.org/10.3109/10408444.2010.530224.

(27) MacKay, D.; Arnot, J. A. The Application of Fugacity and Activity to Simulating the Environmental Fate of Organic Contaminants. J. Chem. Eng. Data 2011, 56 (4), 1348-1355. https://doi.org/10.1021/je101158y.

(28) Burkhard, L. P.; Arnot, J. A.; Embry, M. R.; Farley, K. J.; Hoke, R. A.; Kitano, M.; Leslie, H. A.; Lotufo, G. R.; Parkerton, T. F.; Sappington, K. G.; Tomy, G. T.; Woodburn, K. B. Comparing Laboratory and Field Measured Bioaccumulation Endpoints. Integr. Environ. Assess. Manag. 2012, 8 (1), 17-31. https://doi.org/10.1002/ieam.260.

(29) Smith, K. E. C.; Schmidt, S. N.; Dom, N.; Blust, R.; Holmstrup, M.; Mayer, P. Baseline Toxic Mixtures of Non-Toxic Chemicals: "Solubility Addition" Increases Exposure for Solid Hydrophobic Chemicals. Environ. Sci. Technol. 2013, 47 (4), 2026-2033. https://doi.org/10.1021/es3040472.

(30) Karadzovska, D.; Brooks, J. D.; Monteiro-Riviere, N. A.; Riviere, J. E. Predicting Skin Permeability from Complex Vehicles. Adv. Drug Deliv. Rev. 2013, 65 (2), 265-277. https://doi.org/10.1016/j.addr.2012.01.019.

(31) Gobas, F. A. P. C.; Xu, S.; Kozerski, G.; Powell, D. E.; Woodburn, K. B.; Mackay, D.; Fairbrother, A. Fugacity and Activity Analysis of the Bioaccumulation and Environmental 
Risks of Decamethylcyclopentasiloxane (D5). Environ. Toxicol. Chem. 2015, 34 (12), 2723-2731. https://doi.org/10.1002/etc.2942.

710

711

712

713

714

715

716

717

718

719

720

721

722

723

724

725

726

727

728

729

730

731

732

733

734

(32) Inostroza, P. A.; Massei, R.; Wild, R.; Krauss, M.; Brack, W. Chemical Activity and Distribution of Emerging Pollutants: Insights from a Multi-Compartment Analysis of a Freshwater System. Environ. Pollut. 2017, 231, 339-347. https://doi.org/10.1016/j.envpol.2017.08.015.

(33) Gobas, F. A. P. C.; Mayer, P.; Parkerton, T. F.; Burgess, R. M.; van de Meent, D.; Gouin, T. A Chemical Activity Approach to Exposure and Risk Assessment of Chemicals: Focus Articles Are Part of a Regular Series Intended to Sharpen Understanding of Current and Emerging Topics of Interest to the Scientific Community. Environ. Toxicol. Chem. 2018, 37 (5), 1235-1251. https://doi.org/10.1002/etc.4091.

(34) Cahill, T. M.; Cousins, I.; Mackay, D. General Fugacity-Based Model to Predict the Environmental Fate of Multiple Chemical Species. Environ. Toxicol. Chem. 2003, 22 (3), 483-493. https://doi.org/10.1002/etc.5620220304.

(35) Bruhn, R.; Lakaschus, S.; McLachlan, M. S. Air/Sea Gas Exchange of PCBs in the Southern Baltic Sea. Atmos. Environ. 2003, 37 (24), 3445-3454. https://doi.org/10.1016/S13522310(03)00329-7.

(36) Maeder, V.; Escher, B. I.; Scheringer, M.; Hungerbühler, K. Toxic Ratio as an Indicator of the Intrinsic Toxicity in the Assessment of Persistent, Bioacculumulative, and Toxic Chemicals. Environ. Sci. Technol. 2004, 38 (13), 3659-3666. https://doi.org/10.1021/es0351591.

(37) Bennett, D. H.; Furtaw, E. J. Fugacity-Based Indoor Residential Pesticide Fate Model. Environ. Sci. Technol. 2004, 38 (7), 2142-2152. https://doi.org/10.1021/es034287m.

(38) Reichenberg, F.; Mayer, P. Two Complementary Sides of Bioavailability : Accessibility and Chemical Activity of Organic Contaminants in Sediments and Soils. Environ. Toxicol. Chem. 2006, 25 (May), 1239-1245.

(39) Nfon, E.; Cousins, I. T. Modelling PCB Bioaccumulation in a Baltic Food Web. Environ. 
Pollut. 2007, 148 (1), 73-82. https://doi.org/10.1016/j.envpol.2006.11.033.

736

737

738

739

740

741

742

743

744

745

746

747

748

749

750

751

752

753

754

755

756

757

758

759

760

761

(40) Mayer, P.; Holmstrup, M. Passive Dosing of Soil Invertebrates with Polycyclic Aromatic Hydrocarbons: Limited Chemical Activity Explains Toxicity Cutoff. Environ. Sci. Technol. 2008, 42 (19), 7516-7521. https://doi.org/10.1021/es801689y.

(41) Mackay, D.; Arnot, J. A.; Petkova, E. P.; Wallace, K. B.; Call, D. J.; Brooke, L. T.; Veith, G. D. The Physicochemical Basis of QSARs for Baseline Toxicity. SAR QSAR Environ. Res. 2009, 20 (3-4), 393-414. https://doi.org/10.1080/10629360902949153.

(42) Morrison, G. C.; Weschler, C. J.; Bekö, G.; Koch, H. M.; Salthammer, T.; Schripp, T.; Toftum, J.; Clausen, G. Role of Clothing in Both Accelerating and Impeding Dermal Absorption of Airborne SVOCs. J. Expo. Sci. Environ. Epidemiol. 2016, 26 (1), 113-118. https://doi.org/10.1038/jes.2015.42.

(43) Morrison, G. C.; Bekö, G.; Weschler, C. J.; Schripp, T.; Salthammer, T.; Hill, J.; Andersson, A. M.; Toftum, J.; Clausen, G.; Frederiksen, H. Dermal Uptake of Benzophenone-3 from Clothing. Environ. Sci. Technol. 2017, 51 (19), 11371-11379. https://doi.org/10.1021/acs.est.7b02623.

(44) Bekö, G.; Morrison, G.; Weschler, C. J.; Koch, H. M.; Pälmke, C.; Salthammer, T.; Schripp, T.; Eftekhari, A.; Toftum, J.; Clausen, G. Dermal Uptake of Nicotine from Air and Clothing: Experimental Verification. Indoor Air 2018, 28 (2), 247-257. https://doi.org/10.1111/ina.12437.

(45) Xu, X.; Weisel, C. P. Dermal Uptake of Chloroform and Haloketones during Bathing. J. Expo. Anal. Environ. Epidemiol. 2005, $15 \quad$ (4), 289-296. https://doi.org/10.1038/sj.jea.7500404.

(46) Guo, Y.; Kannan, K. A Survey of Phthalates and Parabens in Personal Care Products from the United States and Its Implications for Human Exposure. Environ. Sci. Technol. 2013, 47 (24), 14442-14449. https://doi.org/10.1021/es4042034.

(47) Lu, S.; Yu, Y.; Ren, L.; Zhang, X.; Liu, G.; Yu, Y. Estimation of Intake and Uptake of Bisphenols and Triclosan from Personal Care Products by Dermal Contact. Sci. Total 
Environ. 2017, 621, 1389-1396. https://doi.org/10.1016/j.scitotenv.2017.10.088.

763

764

765

766

767

768

769

770

771

772

773

774

775

776

777

778

779

780

781

782

783

784

785

786

787

788

(48) Homem, V.; Silva, E.; Alves, A.; Santos, L. Scented Traces - Dermal Exposure of Synthetic Musk Fragrances in Personal Care Products and Environmental Input Assessment. J. Nurse Pract. 2015, 11 (9), 276-287. https://doi.org/10.1016/j.chemosphere.2015.06.078.

(49) Philippat, C.; Bennett, D.; Calafat, A. M.; Picciotto, I. H. Exposure to Select Phthalates and Phenols through Use of Personal Care Products among Californian Adults and Their Children. Environ. Res. 2015, 140, 369-376. https://doi.org/10.1016/j.envres.2015.04.009.

(50) Koniecki, D.; Wang, R.; Moody, R. P.; Zhu, J. Phthalates in Cosmetic and Personal Care Products: Concentrations and Possible Dermal Exposure. Environ. Res. 2011, 111 (3), 329336. https://doi.org/10.1016/j.envres.2011.01.013.

(51) Sandanger, T. M.; Huber, S.; Moe, M. K.; Braathen, T.; Leknes, H.; Lund, E. Plasma Concentrations of Parabens in Postmenopausal Women and Self-Reported Use of Personal Care Products: The NOWAC Postgenome Study. J. Expo. Sci. Environ. Epidemiol. 2011, 21 (6), 595-600. https://doi.org/10.1038/jes.2011.22.

(52) Sakhi, A. K.; Sabaredzovic, A.; Cequier, E.; Thomsen, C. Phthalate Metabolites in Norwegian Mothers and Children: Levels, Diurnal Variation and Use of Personal Care Products. Sci. Total Environ. 2017, 599-600, 1984-1992. https://doi.org/10.1016/j.scitotenv.2017.05.109.

(53) Preau, J. L.; Wong, L. Y.; Silva, M. J.; Needham, L. L.; Calafat, A. M. Variability over 1 Week in the Urinary Concentrations of Metabolites of Diethyl Phthalate and Di(2Ethylhexyl) Phthalate among Eight Adults: An Observational Study. Environ. Health Perspect. 2010, 118 (12), 1748-1754. https://doi.org/10.1289/ehp.1002231.

(54) Koch, H. M.; Lorber, M.; Christensen, K. L. Y.; Pälmke, C.; Koslitz, S.; Brüning, T. Identifying Sources of Phthalate Exposure with Human Biomonitoring: Results of a $48 \mathrm{~h}$ Fasting Study with Urine Collection and Personal Activity Patterns. Int. J. Hyg. Environ. Health 2013, 216, 672-681. https://doi.org/10.1016/j.jheh.2012.12.002.

(55) Draelos, Z. D. What's in a Formulation? Cosmetic Dermatology. November 2003, pp 56- 
58.

790

791

792

793

794

795

796

797

798

799

800

801

802

803

804

805

806

807

808

809

810

811

812

813

814

815

(56) Azeem, A.; Rizwan, M.; Ahmad, F.; Khan, Z.; Khar, R.; Aqil, M.; Talegaonkar, S. Emerging Role of Microemulsions in Cosmetics. Recent Pat. Drug Deliv. Formul. 2008, 2 (3), 275-289. https://doi.org/10.2174/187221108786241624.

(57) Lee, C. K. H.; Choy, K. L.; Chan, Y. N. A Knowledge-Based Ingredient Formulation System for Chemical Product Development in the Personal Care Industry. Comput. Chem. Eng. 2014, 65, 40-53. https://doi.org/10.1016/j.compchemeng.2014.03.004.

(58) Nohynek, G. J.; Dufour, E. K. Nano-Sized Cosmetic Formulations or Solid Nanoparticles in Sunscreens: A Risk to Human Health? Arch. Toxicol. 2012, 86 (7), 1063-1075. https://doi.org/10.1007/s00204-012-0831-5.

(59) Morrison, G. C.; Weschler, C. J.; Bekö, G. Dermal Uptake Directly from Air under Transient Conditions: Advances in Modeling and Comparisons with Experimental Results for Human Subjects. Indoor Air 2016, 26 (6), 913-924. https://doi.org/10.1111/ina.12277.

(60) Michael, H.; McLachlan, M. S. Initial Development of a Solid-Phase Fugacity Meter for Semivolatile Organic Compounds. Environ. Sci. Technol. 1992, 26 (8), 1643-1649. https://doi.org/10.1021/es00032a024.

(61) Wilcockson, J. B.; Gobas, F. A. P. C. Thin-Film Solid-Phase Extraction to Measure Fugacities of Organic Chemicals with Low Volatility in Biological Samples. Environ. Sci. Technol. 2001, 35 (7), 1425-1431. https://doi.org/10.1021/es001561t.

(62) Leslie, H. A.; Oosthoek, A. J. P.; Busser, F. J. M.; Kraak, M. H. S.; Hermens, J. L. M. Biomimetic Solid-Phase Microextraction to Predict Body Residues and Toxicity of Chemicals That Act by Narcosis. Environ. Toxicol. Chem. 2002, 21 (2), 229-234. https://doi.org/10.1002/etc.5620210202.

(63) Leslie, H. A.; Hermens, J. L. M.; Kraak, M. H. S. Baseline Toxicity of a Chlorobenzene Mixture and Total Body Residues Measured and Estimated with Solid-Phase Microextraction. Environ. Toxicol. Chem. 2004, 23 (8), 2017-2021. https://doi.org/10.1897/03-386. 
816 (64) Legind, C. N.; Karlson, U.; Burken, J. G.; Reichenberg, F.; Mayer, P. Determining Chemical Activity of (Semi)Volatile Compounds by Headspace Solid-Phase

(65) Hunter, W.; Xu, Y.; Spurlock, F.; Gan, J. Using Disposable Polydimethylsiloxane Fibers to Assess the Bioavailability of Permethrin in Sediment. Environ. Toxicol. Chem. 2008, 27 (3), 568-575. https://doi.org/10.1897/07-335.1.

(66) Van Der Heijden, S. A.; Jonker, M. T. O. PAH Bioavailability in Field Sediments: Comparing Different Methods for Predicting in Situ Bioaccumulation. Environ. Sci. Technol. 2009, 43 (10), 3757-3763. https://doi.org/10.1021/es803329p.

(69) Haftka, J. J. H.; Parsons, J. R.; Govers, H. A. J. Supercooled Liquid Vapour Pressures and Related Thermodynamic Properties of Polycyclic Aromatic Hydrocarbons Determined by https://doi.org/10.1016/j.chroma.2006.09.050. Environ. Toxicol. Chem. 2012, 31 (9), 2159-2167. https://doi.org/10.1002/etc.1935.

Microextraction to Estimate Toxicity: Relating Fiber Concentrations to Body Residues-Part II. Environ. Toxicol. Chem. 2012, 31 (9), 2168-2174. https://doi.org/10.1002/etc.1936.

\section{https://doi.org/10.1016/j.chroma.2006.09.050.}

70) Umnahanant, P.; Chickos, J. An Examination of the Thermodynamics of Fusion, Vaporization, and Sublimation of Several Parabens by Correlation Gas Chromatography. J. Pharm. Sci. 2011, 100 (5), 1847-1855. https://doi.org/10.1002/jps.22423.

(71) Cleek, R. L.; Bunge, a. L. A New Method for Estimating Dermal Absorption from Chemical Exposure. 1. General Approach. Pharm. Res. 1993, 10 (4), 497-506. https://doi.org/10.1023/A:1018981515480.

72) Moos, R. K.; Angerer, J.; Dierkes, G.; Brüning, T.; Koch, H. M. Metabolism and Elimination of Methyl, Iso- and n-Butyl Paraben in Human Urine after Single Oral Dosage. 
Arch. Toxicol. 2016, 90 (11), 2699-2709. https://doi.org/10.1007/s00204-015-1636-0.

844

845

846

847

848

849

850

851

852

853

854

855

856

857

858

859

860

861

862

863

864

865

866

867

868

(73) Koch, H. M.; Christensen, K. L. Y.; Harth, V.; Lorber, M.; Brüning, T. Di-n-Butyl Phthalate (DnBP) and Diisobutyl Phthalate (DiBP) Metabolism in a Human Volunteer after Single Oral Doses. Arch. Toxicol. 2012, 86 (12), 1829-1839. https://doi.org/10.1007/s00204-0120908-1.

(74) Gong, M.; Zhang, Y.; Weschler, C. J. Predicting Dermal Absorption of Gas-Phase Chemicals: Transient Model Development, Evaluation, and Application. Indoor Air 2014, 24 (3), 292-306. https://doi.org/10.1111/ina.12079.

(75) Nitsche, J. M.; Wang, T.-F.; Kasting, G. B. A Two-Phase Analysis of Solute Partitioning into the Stratum Corneum. J. Pharm. Sci. 2006, 95 (3), 649-666. https://doi.org/10.1002/jps.20549.

(76) Wang, T. F.; Kasting, G. B.; Nitsche, J. M. A Multiphase Microscopic Diffusion Model for Stratum Corneum Permeability. II. Estimation of Physicochemical Parameters, and Application to a Large Permeability Database. J. Pharm. Sci. 2007, 96 (11), 3024-3051. https://doi.org/10.1002/jps.20883.

(77) Dancik, Y.; Miller, M. A.; Jaworska, J.; Kasting, G. B. Design and Performance of a Spreadsheet-Based Model for Estimating Bioavailability of Chemicals from Dermal Exposure. Adv. Drug Deliv. Rev. 2013, 65 (2), 221-236. https://doi.org/10.1016/j.addr.2012.01.006.

(78) Bunge, A. L.; Cleek, R. L. A New Method for Estimating Dermal Absorption from Chemical Exposure: 2. Effect of Molecular Weight and Octanol-Water Partitioning. Pharm. Res. 1995, 12 (1), 88-95. https://doi.org/10.1023/A:1016242821610.

(79) Rushmer, R. F.; K Buettner, K. J.; Short, J. M. The Skin; 1966; Vol. 154.

(80) Reddy, M. B.; Guy, R. H.; Bunge, A. L. Does Epidermal Turnover Reduce Percutaneous Penetration? Pharm. Res. 2000, $17 \quad$ (11), 1414-1419. https://doi.org/10.1023/A:1007522200422. 
869 (81) Egawa, M.; Hirao, T.; Takahashi, M. In Vivo Estimation of Stratum Corneum Thickness from Water Concentration Profiles Obtained with Raman Spectroscopy. Acta Derm. Venereol. 2007, 87 (1), 4-8. https://doi.org/10.2340/00015555-0183.

(82) Morrison, G. C.; Weschler, C. J.; Bekö, G. Dermal Uptake of Phthalates from Clothing: Comparison of Model to Human Participant Results. Indoor Air 2017, 27 (3), 642-649. https://doi.org/10.1111/ina.12354.

(83) Chudecka, M.; Lubkowska, A. Thermal Maps of Young Women and Men. Infrared Phys. Technol. 2015, 69, 81-87. https://doi.org/10.1016/j.infrared.2015.01.012.

(84) Savastano, D. M.; Gorbach, A. M.; Eden, H. S.; Brady, S. M.; Reynolds, J. C.; Yanovski, J. A. Adiposity and Human Regional Body Temperature. Am. J. Clin. Nutr. 2009, 90 (5), 1124-1131. https://doi.org/10.3945/ajcn.2009.27567.

(85) Mehnert, P.; Malchaire, J.; Kampmann, B.; Piette, A.; Griefahn, B.; Gebhardt, H. Prediction of the Average Skin Temperature in Warm and Hot Environments; 2000; Vol. 82. https://doi.org/10.1007/s004210050651.

(86) Baldus, S.; Kluth, K.; Strasser, H. Order-Picking in Deep Cold - Physiological Responses of Younger and Older Females. Part 2: Body Core Temperature and Skin Surface Temperature. Work 2012, 41 (SUPPL.1), 3010-3017. https://doi.org/10.3233/WOR-20120557-3010.

(87) Yeom, D.; Choi, J. H.; Kang, S. H. Investigation of the Physiological Differences in the Immersive Virtual Reality Environment and Real Indoor Environment: Focused on Skin Temperature and Thermal Sensation. Build. Environ. 2019, 154, 44-54. https://doi.org/10.1016/j.buildenv.2019.03.013.

(88) Trac, L. N.; Schmidt, S. N.; Holmstrup, M.; Mayer, P. Headspace Passive Dosing of Volatile Hydrophobic Organic Chemicals from a Lipid Donor - Linking Their Toxicity to Well-Defined Exposure for an Improved Risk Assessment. Environ. Sci. Technol. 2019. https://doi.org/10.1021/acs.est.9b04681. 
896

897

898

899

900

901

902

903

904

905

906

907

908

909

910

911

912

913

914

915

916

917

918

919

920

921

3. The Effect of Temperature on the Transport of Non-Electrolytes across the Skin. J Invest Dermatol 1967, 49 (6), 582-589. https://doi.org/10.1038/jid.1967.184.

(90) Cummings, E. G. Temperature and Concentration Effects on Penetration of N-Octylamine through Human Skin in Situ.; 1969; Vol. 53. https://doi.org/10.1038/jid.1969.109.

(91) Peck, K. D.; Ghanem, A. -H; Higuchi, W. I. The Effect of Temperature upon the Permeation of Polar and Ionic Solutes through Human Epidermal Membrane. J. Pharm. Sci. 1995, 84 (8), 975-982. https://doi.org/10.1002/jps.2600840813.

(92) Akomeah, F.; Nazir, T.; Martin, G. P.; Brown, M. B. Effect of Heat on the Percutaneous Absorption and Skin Retention of Three Model Penetrants. Eur. J. Pharm. Sci. 2004, 21 (23), 337-345. https://doi.org/10.1016/j.ejps.2003.10.025.

(93) Mitragotri, S. Temperature Dependence of Skin Permeability to Hydrophilic and Hydrophobic Solutes. J. Pharm. Sci. 2007, 96 (7), 1832-1839. https://doi.org/10.1002/jps.20793.

(94) Shahzad, Y.; Louw, R.; Gerber, M.; Du Plessis, J. Breaching the Skin Barrier through Temperature Modulations. Journal of Controlled Release. Elsevier B.V. March 28, 2015, pp 1-13. https://doi.org/10.1016/j.jconrel.2015.01.019.

(95) Callahan, P. J.; Kenny, D. V.; Gordon, S. M.; Brinkman, M. C.; Wallace, L. A. Effect of Water Temperature on Dermal Exposure to Chloroform; 2007; Vol. 106. https://doi.org/10.2307/3434040.

(96) Tominaga, K.; Tojo, K. Effect of Environmental Temperature on Transdermal Drug Penetration. Biol. Pharm. Bull. 2010, 33 (12), 1983-1987. https://doi.org/10.1248/bpb.33.1983.

(97) Ngo, M. A.; O’Malley, M.; Maibach, H. I. Percutaneous Absorption and Exposure Assessment of Pesticides. J. Appl. Toxicol. 2010, 30 (2), 91-114. https://doi.org/10.1002/jat.1505.

(98) Kasting, G. B. Kinetics of Finite Dose Absorption through Skin 1. Vanillylnonanamide. $J$. 
Pharm. Sci. 2001, $90 \quad$ (2), 202-212. https://doi.org/10.1002/15206017(200102)90:2<202::AID-JPS11>3.0.CO;2-E.

924

925

926

927

928

929

930

931

932

933

934

935

936

937

938

939

940

941

942

943

944

945

946

947

948

(99) Kissel, J. C. The Mismeasure of Dermal Absorption. J. Expo. Sci. Environ. Epidemiol. 2011, 21 (3), 302-309. https://doi.org/10.1038/jes.2010.22.

(100) Frasch, H. F.; Dotson, G. S.; Bunge, A. L.; Chen, C.-P. P.; Cherrie, J. W.; Kasting, G. B.; Kissel, J. C.; Sahmel, J.; Semple, S.; Wilkinson, S. Analysis of Finite Dose Dermal Absorption Data: Implications for Dermal Exposure Assessment. J. Expo. Sci. Environ. Epidemiol. 2014, 24 (1), 65-73. https://doi.org/10.1038/jes.2013.23.

(101) Blank, I. H.; Moloney, J.; Emslie, A. G. The Diffusion of Water across the Stratum Corneum as a Function of Its Water Content; 1984; Vol. 82. https://doi.org/10.1111/15231747.ep12259835.

(102) Zhai, H.; Ebel, J. P.; Chatterjee, R.; Stone, K. J.; Gartstein, V.; Juhlin, K. D.; Pelosi, A.; Maibach, H. I. Hydration vs. Skin Permeability to Nicotinates in Man. Ski. Res. Technol. 2002, 8 (1), 13-18. https://doi.org/10.1046/j.0909-752x.2001.10312.x.

(103) Dąbrowska, A. K.; Adlhart, C.; Spano, F.; Rotaru, G.-M.; Derler, S.; Zhai, L.; Spencer, N. D.; Rossi, R. M. In Vivo Confirmation of Hydration-Induced Changes in Human-Skin Thickness, Roughness and Interaction with the Environment. Biointerphases 2016, 11 (3), 031015. https://doi.org/10.1116/1.4962547.

(104) Yousef, S.; Mohammed, Y.; Namjoshi, S.; Grice, J.; Sakran, W.; Roberts, M. Mechanistic Evaluation of Hydration Effects on the Human Epidermal Permeation of Salicylate Esters. AAPS J. 2016, 19 (1), 180-190. https://doi.org/10.1208/s12248-016-9984-0.

(105) Scheuplein, R. J.; Blank, I. H. Permeability of the Skin. Physiol. Rev. 1971, 51 (4), $702-$ 747. https://doi.org/10.1152/physrev.1971.51.4.702.

(106) Alonso, A.; Meirelles, N. C.; Yushmanov, V. E.; Tabak, M. Water Increases the Fluidity of Intercellular Membranes of Stratum Corneum: Correlation with Water Permeability, Elastic, and Electrical Resistance Properties. J. Invest. Dermatol. 1996, 106 (5), 1058-1063. https://doi.org/10.1111/1523-1747.ep12338682. 
949

950

951

952

953

954

955

956

957

958

959

960

961

962

963

964

965

966

967

968

969

970

971

972

973

974

975

(107) Spencer, N. D.; Adlhart, C.; Rossi, R. M.; Derler, S.; Spano, F.; Dąbrowska, A. K.; Rotaru, G.-M.; Zhai, L. In Vivo Confirmation of Hydration-Induced Changes in Human-Skin Thickness, Roughness and Interaction with the Environment . Biointerphases 2016, 11 (3), 031015. https://doi.org/10.1116/1.4962547.

(108) Caussin, J.; Groenink, H. W. W.; de Graaff, A. M.; Gooris, G. S.; Wiechers, J. W.; Van Aelst, A. C.; Bouwstra, J. A. Lipophilic and Hydrophilic Moisturizers Show Different Actions on Human Skin as Revealed by Cryo Scanning Electron Microscopy. Exp. Dermatol. 2007, 16 (11), 891-898. https://doi.org/10.1111/j.1600-0625.2007.00596.x.

(109) Crowther, J. M.; Sieg, A.; Blenkiron, P.; Marcott, C.; Matts, P. J.; Kaczvinsky, J. R.; Rawlings, A. V. Measuring the Effects of Topical Moisturizers on Changes in Stratum Corneum Thickness, Water Gradients and Hydration in Vivo. Br. J. Dermatol. 2008, 159 (3), 567-577. https://doi.org/10.1111/j.1365-2133.2008.08703.x.

(110) Liu, X.; Grice, J. E.; Lademann, J.; Otberg, N.; Trauer, S.; Patzelt, A.; Roberts, M. S. Hair Follicles Contribute Significantly to Penetration through Human Skin Only at Times Soon after Application as a Solvent Deposited Solid in Man. Br. J. Clin. Pharmacol. 2011, 72 (5), 768-774. https://doi.org/10.1111/j.1365-2125.2011.04022.x.

(111) Frum, Y.; Bonner, M. C.; Eccleston, G. M.; Meidan, V. M. The Influence of Drug Partition Coefficient on Follicular Penetration: In Vitro Human Skin Studies. Eur. J. Pharm. Sci. 2007, 30 (3-4), 280-287. https://doi.org/10.1016/j.ejps.2006.11.014.

(112) Semple, S.; Brouwer, D. H.; Dick, F.; Cherrie, J. W. A Dermal Model for Spray Painters. Part II: Estimating the Deposition and Uptake of Solvents. Ann. Occup. Hyg. 2001, 45 (1), 25-33. https://doi.org/10.1016/S0003-4878(00)00007-7.

(113) Afshari, A.; Gunnarsen, L.; Clausen, P. A.; Hansen, V. Emission of Phthalates from PVC and Other Materials. Indoor Air 2004, 14 (2), 120-128. https://doi.org/10.1046/j.16000668.2003.00220.x.

(114) Jeon, S.; Kim, K. T.; Choi, K. Migration of DEHP and DINP into Dust from PVC Flooring Products at Different Surface Temperature. Sci. Total Environ. 2016, 547, 441-446. 
$976 \quad$ https://doi.org/10.1016/j.scitotenv.2015.12.135.

977 (115) Chao, Y. C. E.; Gibson, R. L.; Nylander-French, L. A. Dermal Exposure to Jet Fuel (JP-8)

978 in US Air Force Personnel. Ann. Occup. Hyg. 2005, 49 (7), 639-645. $979 \quad$ https://doi.org/10.1093/annhyg/mei021.

980 


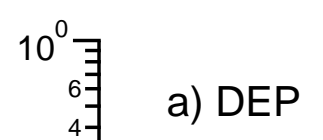

a) DEP
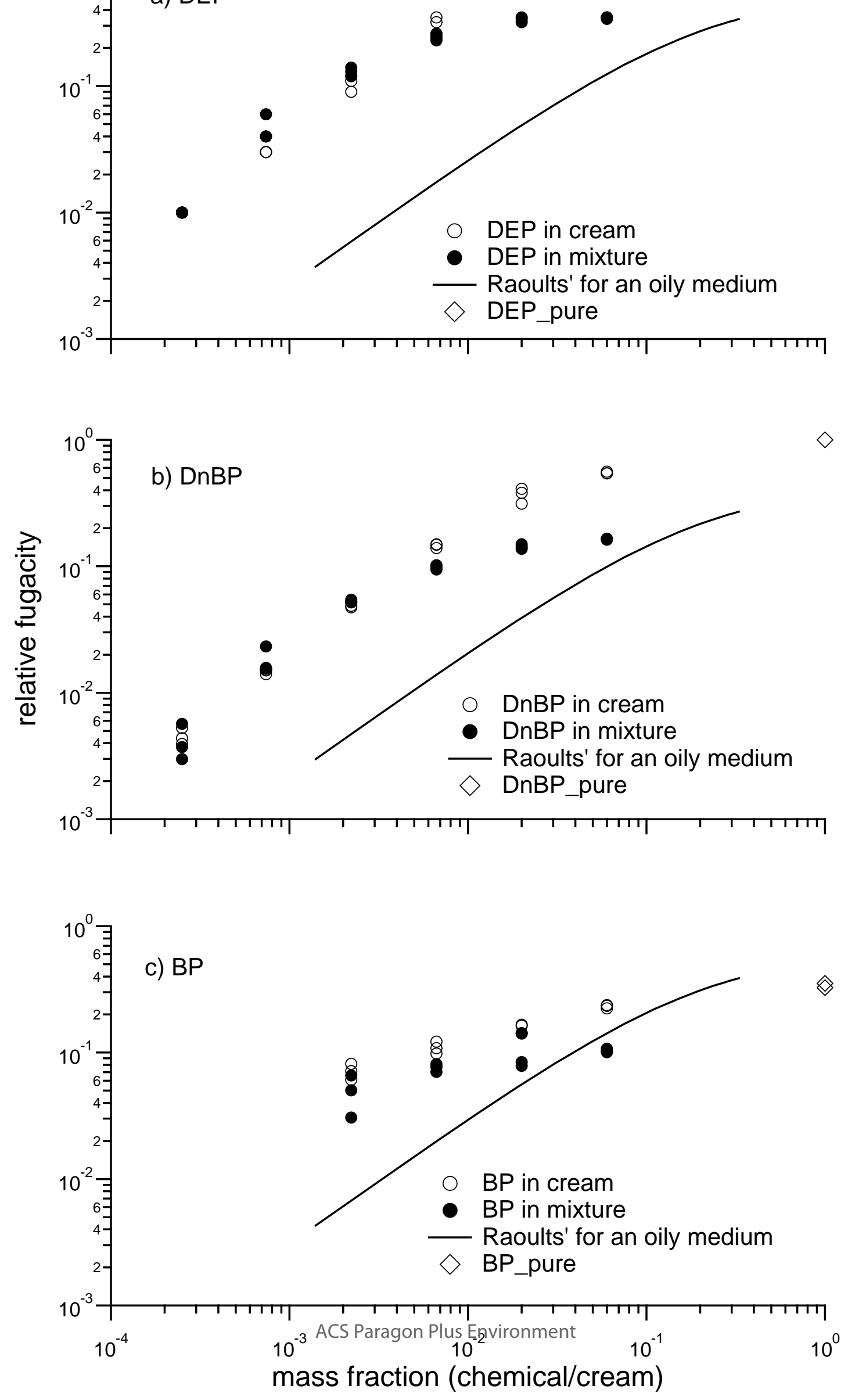
Environmental Science \& Technology
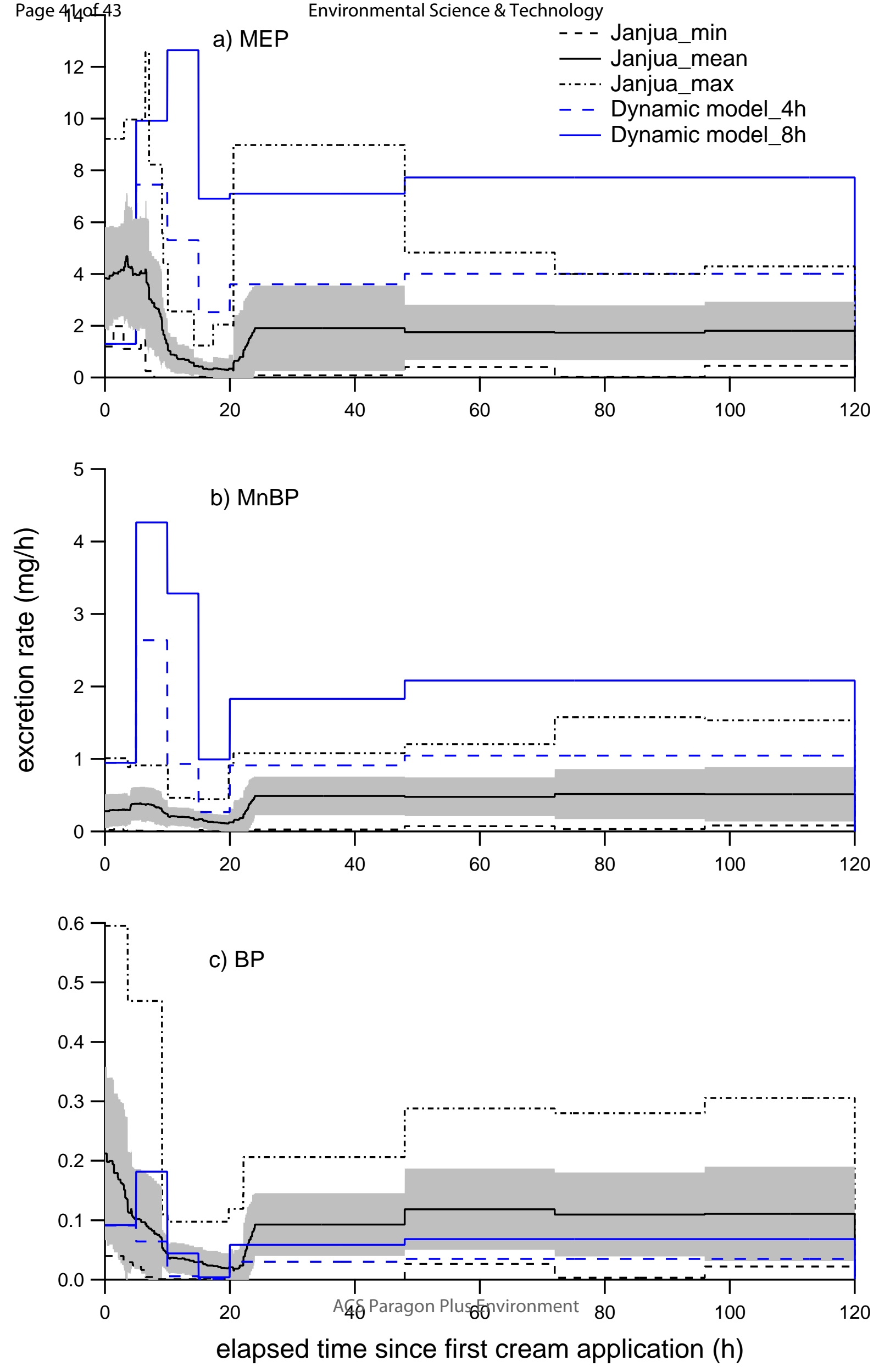

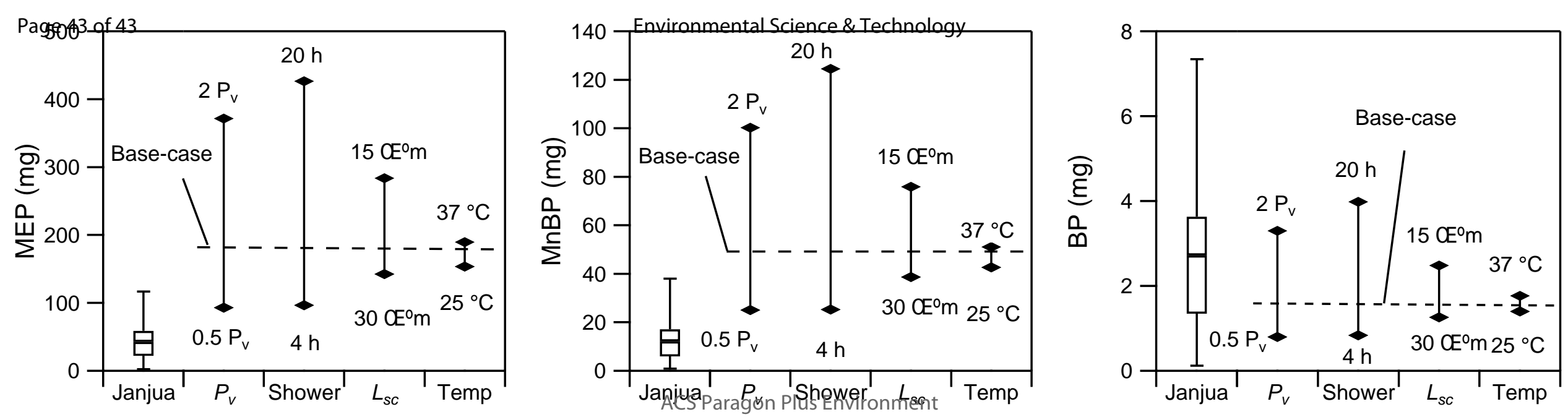